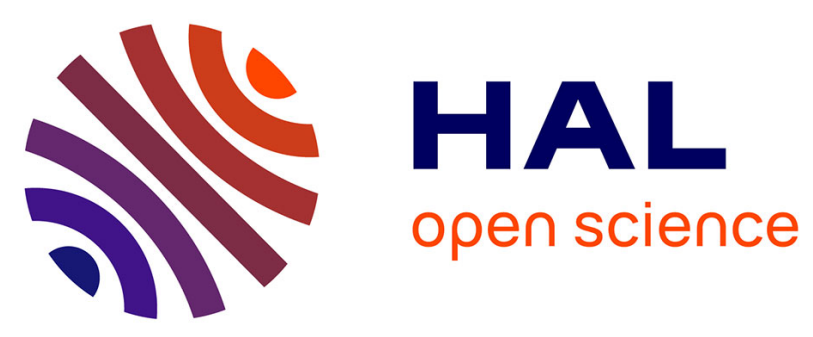

\title{
SIRT1 activation rescues the mislocalization of RNA-binding proteins and cognitive defects induced by inherited cobalamin disorders
}

Rose Ghemrawi, Carole Arnold, Shyue-Fang Battaglia-Hsu, Grégory Pourié, Isabelle Trinh, Christine Bassila, Charif Rashka, Arnaud Wiedemann, Justine Flayac, Aurélie Robert, et al.

\section{To cite this version:}

Rose Ghemrawi, Carole Arnold, Shyue-Fang Battaglia-Hsu, Grégory Pourié, Isabelle Trinh, et al.. SIRT1 activation rescues the mislocalization of RNA-binding proteins and cognitive defects induced by inherited cobalamin disorders. Metabolism, 2019, 101 (7), pp.153992. 10.1016/j.metabol.2019.153992 . hal-02507780

\section{HAL Id: hal-02507780 \\ https://hal.univ-lorraine.fr/hal-02507780}

Submitted on 21 Dec 2021

HAL is a multi-disciplinary open access archive for the deposit and dissemination of scientific research documents, whether they are published or not. The documents may come from teaching and research institutions in France or abroad, or from public or private research centers.
L'archive ouverte pluridisciplinaire HAL, est destinée au dépôt et à la diffusion de documents scientifiques de niveau recherche, publiés ou non, émanant des établissements d'enseignement et de recherche français ou étrangers, des laboratoires publics ou privés.

\section{(ㄷ)(1) $\$$}

Distributed under a Creative Commons Attribution - NonCommerciall 4.0 International 


\section{SIRT1 activation rescues the mislocalization of RNA-binding proteins and cognitive defects induced} by inherited cobalamin disorders

Rose Ghemrawi ${ }^{\text {a }}$, Carole Arnold ${ }^{\text {a }}$, Shyue-Fang Battaglia-Hsu ${ }^{\text {a }}$, Grégory Pourié ${ }^{\mathrm{a}}$, Isabelle Trinh ${ }^{\mathrm{a}}$, Christine Bassila ${ }^{\text {a }}$ Rashka Charif ${ }^{\text {a }}$, Arnaud Wiedemann ${ }^{\text {a, }}{ }^{\text {, }}$, Justine Flayac ${ }^{\text {a }}$, Aurélie Robert ${ }^{\text {a }}$, Natacha Dreumont $^{\mathrm{a}}$, François Feillet ${ }^{\mathrm{a}, \mathrm{b}}$, Jean-Louis Guéant ${ }^{\mathrm{a}, \mathrm{b}, 1}$, David Coelho ${ }^{\mathrm{a}, \mathrm{b}, 1, *}$

${ }^{a}$ Université de Lorraine, Inserm, UMRS 1256, NGERE - Nutrition, Genetics, and Environmental Risk Exposure, F-54000 Nancy, France.

${ }^{\mathrm{b}}$ Université de Lorraine, CHRU-Nancy, National Center of Inborn Errors of Metabolism, F-54000 Nancy, France.

* Correspondance to: David Coelho, Inserm-UL U1256 - NGERE, Faculté de Médecine, Bâtiment C 2ème étage, 9 Avenue de la Forêt de Haye, BP50184, 54505 Vandœuvre-lès-Nancy, France. Telephone: +33 (0)3 72746150 ; E-mail : david.coelho@inserm.fr

E-mail addresses: rose.ghemrawi@hotmail.com (R. Ghemrawi), carole.arnold@inserm.fr (C.Arnold), shyue-fang.battaglia@univ-lorraine.fr (SF Battaglia-Hsu), gregory.pourie@univ-lorraine.fr (G. Pourié), isabelle.trinh6@etu.univ-lorraine.fr (I. Trinh), christine_bassila@ hotmail.com (C. Bassila), charif.rashka@univ-lorraine.fr (R. Charif),arnaud.wiedemann@gmail.com (A. Wiedemann), justine.flayac@univ-lorraine.fr (J. Flayac), aurelie.robert@univ-lorraine.fr (A. Robert), natacha.dreumont@univ-lorraine.fr (N. Dreumont), f.feillet@chru-nancy.fr (F. Feillet), jeanlouis.gueant@univ-lorraine.fr (JL Guéant).

${ }^{1}$ The last two authors contributed equally to this work. 


\begin{abstract}
Background: The molecular consequences of inborn errors of vitamin B12 or cobalamin metabolism are far from being understood. Moreover, innovative therapeutic strategies are needed for the treatment of neurological outcomes that are usually resistant to conventional treatments. Our previous findings suggest a link between SIRT1, cellular stress and RNA binding proteins (RBP) mislocalization in the pathological mechanisms triggered by impaired vitamin B12 metabolism.
\end{abstract}

Objectives and Methods: The goal of this study was to investigate the effects of the pharmacological activation of SIRT1 using SRT1720 on the molecular mechanisms triggered by impaired methionine synthase activity. Experiments were performed in vitro with fibroblasts from patients with the $c b l G$ and cblC inherited defects of vitamin B12 metabolism and in vivo with an original transgenic mouse model of methionine synthase deficiency specific to neuronal cells. Subcellular localization of the RBPs HuR, HnRNPA1, RBM10, SRSF1 and Y14 was investigated by immunostaining and confocal microscopy in patient fibroblasts. RBPs methylation and phosphorylation were studied by co-immunoprecipitation and proximity ligation assay. Cognitive performance of the transgenic mice treated with SRT1720 was measured with an aquatic maze.

Results: Patient fibroblasts with $c b l C$ and $c b l G$ defects of vitamin B12 metabolism presented with endoplasmic reticulum stress, altered methylation, phosphorylation and subcellular localization of HuR, HnRNPA1 and RBM10, global mRNA mislocalization and increased HnRNPA1-dependent skipping of IRF3 exons. Incubation of fibroblasts with cobalamin, S-adenosyl methionine and okadaic acid rescued the localization of the RBPs and mRNA. The SIRT1 activating compound SRT1720 inhibited ER stress and rescued RBP and mRNA mislocalization and $I R F 3$ splicing. Treatment with this SIRT1 agonist prevented all these hallmarks in patient fibroblasts but it also improved the deficient hippocampodependent learning ability of methionine synthase conditional knock-out mice. 
Conclusions: By unraveling the molecular mechanisms triggered by inborn errors of cbl metabolism associating ER stress, RBP mislocalization and mRNA trafficking, our study opens novel therapeutic perspectives for the treatment of inborn errors of vitamin B12 metabolism.

Keywords: vitamin B12, inherited defect, RNA binding protein, SIRT1, SRT1720, cognitive defect

\section{Introduction}

In man, vitamin B12 or cobalamin (cbl) is essential for normal development and survival. The two cbl coenzymes adenosylcobalamin (AdoCbl) and methylcobalamin (MeCbl) serve as cofactor for two enzymes, methylmalonyl-CoA mutase (MUT, E.C. 5.4.99.2) and methionine synthase (MS, 5-methyltetrahydrofolate: L-homocysteine S-methyltransferase; E.C. 2.1.1.13, encoded by MTR), respectively [1]. Most inborn error of cellular cbl metabolism decrease MS activity and lead to hyperhomocysteinemia and homocystinuria (Supplementary Fig. 1). These inherited defects are classified as complementation groups named $c b l C-G$ and $c b l J$ by fibroblast phenotyping. They include 7 genes, which respectively encode proteins for cellular uptake and transport, including two lysosomal membrane proteins, LMBD1 (cblF) and ABCD4 (cblJ), two cytoplasmic transporters/enzymes, MMACHC ( $c b l C)$ and MMADHC $(c b l D)$ and the two target enzymes of MeCbl, methionine synthase (MS) $(c b l G)$ and methionine synthase reductase (MSR, encoded by MTRR, cblE group) [2, 3].

$\mathrm{CblC}$ is the most common complementation group of inborn errors of intracellular cbl metabolism (MIM\# 277400). It results from mutations in the MMACHC gene, which codes for a cytosolic enzyme responsible for the decyanation and the dealkylation of cyanocobalamin and alkylcobalamins, respectively. Most $c b l C$ patients present with hematologic and neurological pathologies and some of them with optic atrophy or pigmentary retinopathy [4, 5]. Patients with $c b l G$ defect (MIM\# 250940) carry mutations in the MTR gene, which encodes MS. They usually present with hypotonia, megaloblastic 
anemia, developmental delay, and brain atrophy [6]. A subgroup named $c b l G$-variant, noted $c b l G^{*}$ is defined by undetectable MS activity in fibroblasts [7].

The molecular mechanisms underlying the pathophysiology of these genetic defects are far from being completely understood. They are supposed to result from the accumulation of methylmalonic acid and/or homocysteine and the decreased synthesis of methionine, which is the immediate metabolic precursor of Sadenosyl methionine (SAM), the universal methyl donor involved in many essential biochemical processes. Indeed, SAM-dependent methylation of DNA, RNA and proteins such as histones is crucial for epigenomic mechanisms of gene expression and for other acceptor molecules such as neurotransmitters, and membrane phospholipids. However, recent studies have highlighted the role of oxidative stress and the subsequent activation of apoptosis in $c b l A, c b l B, c b l D$-variant 1 and $c b l C(8)$, in $c b l G$ and $c b l E(9)$, and in $c b l C$ and $c b l B$ defects (10). We previously demonstrated that impaired cellular availability of vitamin B12 alters cell proliferation and differentiation [11] and triggers endoplasmic reticulum (ER) stress in murine neuroblastoma N1E115 cells [12]. Impaired cbl metabolism is also associated with disturbances of mRNA nucleocytoplasmic transport related to the subcellular mislocalization of several RNA binding proteins (RBP), including the ELAVL1/HuR stress protein in N1E115 cells [13]. The abnormal HuR subcellular localization is also found in the $C d 320$ knock-out mouse model, in which the cellular uptake of cbl is impaired [13].

The overall aim of our study was to evaluate the molecular mechanisms that could explain the origin of the high variability in clinical presentation and poor response to conventional therapy of inborn errors of cbl metabolism. We found that $c b l C, c b l G$ and $c b l G^{*}$ defects produce a SIRT1-dependent ER stress that leads to altered shuttling and splicing of mRNA through the subcellular mislocalization of stresssensitive RBP, including ELAVL1/HuR, HnRNPA1 and RBM10. Our study opens perspectives for the use of SIRT1 agonists as a novel therapeutic strategy to treat the cases of inborn errors of cbl metabolism with poor response to conventional therapy. 


\section{Material and Methods}

\subsection{Cell culture}

Patient fibroblasts were provided by D.R. Rosenblatt (McGill University Canada; $c b l G * 2)$, M.R. Baumgartner (University Hospital of Zürich, Switzerland; $c b l C 2, c b l C 3, c b l G^{*} 1$ ) and the CHRU Hospital of Nancy, France $(c b l C 1, c b l G 1, c b l G 2)$. The description of cell lines used is presented in Supplementary Table 1. Fibroblasts were grown in Dulbecco's modified Eagle medium supplemented with $10 \%$ heatinactivated fetal calf serum and supplemented with antibiotics. All cells have been used with a similar number of passages, between 10 and 20. Hydroxycobalamin, SAM, okadaic acid, G418, thapsigargin (TG) and Adox were purchased from Sigma (Lyon, France) and SRT1720 from Euromedex (Strasbourg, France) [15]. Cells were treated with hydroxycobalamin $(20 \mu \mathrm{M})$ or SAM $(75 \mu \mathrm{M})$ for 5-7 days. TG, Adox and SRT1720 treatments were done for 3 days at $1 \mu \mathrm{M}$. Okadaic acid treatment was applied for 3 days at $10 \mathrm{nM}$.

\subsection{Western blot}

Western blot experiments were performed as described [13]. ATF6 (Santa Cruz), HuR (Millipore), HnRNPA1 (Santa Cruz), SRSF1 (James Stevenin, IGBMC, Strasbourg), Y14 and RBM10 (Novus Biologicals). Appropriate secondary antibodies conjugated to HRP were used for detection with Clarity Western ECL Substrate (BioRad).

\subsection{Immunoprecipitation}

Immunoprecipitation experiments were performed as described [13] with Phospho-Serine (Millipore) and Methyl-Arginine (Abcam) antibodies.

\subsection{Immunofluorescence}

Fibroblasts were fixed with 4\% paraformaldehyde, permeabilized with PBS- $0.1 \%$ Triton, blocked with 5\% BSA, and incubated with primary antibodies: HuR (Millipore), HnRNPA1 (Santa Cruz), SRSF1 
(James Stevenin, IGBMC, Strasbourg), Y14 and RBM10 (Novus Biologicals) for $100 \mathrm{~min}$ at room temperature and with secondary antibodies for $1 \mathrm{~h}$ at room temperature. Detection of the nucleus was done with 4, 6- diamidino-2-phenylindole (DAPI) (Sigma). Cells were imaged using Nikon C2 confocal microscope with 60x oil immersion lens.

\subsection{Duolink Proximity ligation assay}

The proximity ligation assay (Duolink in situ PLA; Eurogentec, Angers, France) was performed to visualize and quantify interactions. Cells were fixed with paraformaldehyde $4 \%$, blocked with BSA 5\% for $1 \mathrm{~h}$ and incubated with primary antibodies against HuR, HnRNPA1, Phospho-Serine or MethylArginine overnight at $4{ }^{\circ} \mathrm{C}$. A pair of oligonucleotide-labelled secondary antibodies was used according to the manufacturer's instructions. Each dot corresponds to a close interaction. The signals were counted and assigned to a specific subcellular location based on microscopy images by using the Blob-Finder/MatLab freeware.

\subsection{FISH}

Fibroblasts were fixed with paraformaldehyde $\left(15 \mathrm{~min}, 4{ }^{\circ} \mathrm{C}\right)$ and permeabilized with PBS-0.1\% triton for $20 \mathrm{~min}$. A prehybridization was performed for $30 \mathrm{~min}$ at room temperature in a buffer containing $1.2 \mathrm{~mL}$ formamide $40 \%, 300 \mu \mathrm{L} \mathrm{SSC} 20 \mathrm{X}, 4.5 \mu \mathrm{L}$ BSA $10 \mathrm{mg} / \mathrm{mL}, 18 \mu \mathrm{L}$ yeast tRNA 10 $\mu \mathrm{g} / \mu \mathrm{L}$ and $1.2 \mathrm{~mL} \mathrm{H}_{2} \mathrm{O}$. This was followed by hybridization $\left(90 \mathrm{~min}\right.$ at $42^{\circ} \mathrm{C}$ ) with FISH probes (Eurogentec) diluted to $0.2 \mu \mathrm{M}$ in the buffer. The sequence of the polyA tail was oligo (dT) 70 modified in 5' with alexa fluor 546. Detection of the nucleus was done with 4, 6- diamidino-2-phenylindole (DAPI) (Sigma). Cells were imaged using Nikon C2 with x60 oil immersion lens.

\subsection{Splicing analysis}

Total RNA was isolated from cultured cells using the RNeasy Plus Mini extraction kit (Qiagen) followed by a reverse transcription (Reverse Transcription kit, Qiagen). PCR was performed in 35 cycles; 
annealing temperature was $57^{\circ} \mathrm{C}$. The $I R F 3$ primers used were as follows: Forward: 5'-

AGCCTCGAGTTTGAGAGCTACC-3'; Reverse: 5'-GGTATCAGAAGTACTGCCTCCAC-3'. PCR

products were $500 \mathrm{bp}$ (Full-length IRF3; 4 exons), 327 bp (Splicing variant type I: only exon 2 exclusion) and 155 bp (Splicing variant type II: both exon 2 and exon 3 exclusion) [14].

\subsection{Generation of conditional Mtr-KO mice}

The Mtr-KO mouse model was generated in collaboration with the Institut Clinique de la Souris (ICS, Illkirch, France). We used the vector \#CSD 69523 obtained from European Conditional Mouse Mutagenesis program, which is based on the 'Knock-out First' strategy. This vector contains two loxP sites flanking exons 4 and 5 of the $M t r$ gene. The vector was electroporated in C57B1/6 embryonic stem cells. Targeted cells were screened by PCR, confirmed by Southern blot analysis and injected into blastocysts derived from mouse strain C57B1/6 to generate chimeras, which were mated to test their ability to transmit the transgene to their progeny. Selected chimeras were used to create the Mtr-KO mouse line, which was maintained on a $\mathrm{C} 57 \mathrm{Bl} / 6$ background. This line was crossed with a Thy1-Cre line (Stock number 6143, FVB/N-Tg (Thy1-cre)1Vln/J, Jackson Institute, USA) to induce Mtr deletion in the central nervous system. Genotyping by PCR was performed on DNA extracted from tail samples, using specific primers and internal PCR controls.

\section{9. $\quad R T-q P C R$}

Total RNA from cortex and hippocampus samples were purified by phenol-chloroform extraction. Reverse transcription was done using the PrimeScript RT Takara System (Ozyme, Saint Quentin-enYvelines, France) according to manufacturer's instructions. Quantitative PCR was performed with SYBR Premix Ex Taq Tli RNaseH Plus system (Ozyme, Saint Quentin-en-Yvelines, France) with Mtr primers (Forward ACACTTGGCCTACCGGATG and Reverse CCAGCCACAAACCTCTTGAC) and Polymerase II primers (Forward AGCAAGCGGTTCCAGAGAAG and Reverse TCCCGAACACTGACATATCTCA). 


\subsection{Immunofluorescent labelling of mouse samples}

Mouse brain hemispheres were fixed by Carnoy's solution, dehydrated and imbedded in paraffin by Leica ASP300-S Dewaxed (Histo Clear; National Diagnostics, HS-200). Sagittal brain sections were rehydrated using standard protocol, and incubated at $95^{\circ} \mathrm{C}$ for 30 minutes in a sodium EDTA solution for antigen retrieval. Brain slices were blocked at $4^{\circ} \mathrm{C}$ overnight with PBS-Triton 0,1\% - BSA 10\% (SIRT1) or PBS-Triton 0,1\% - Horse Serum 5\% - BSA 10\% (HuR). They were incubated overnight in a humid chamber at $4^{\circ} \mathrm{C}$ with primary antibodies: SIRT1 (1/50, Sc-15404, Santa Cruz, Dallas, USA) and HuR (1/200, 07-468, Merck, Darmstadt, Germany), washed in BSA/PBS-Triton and incubated with secondary antibody coupled to Alexa Fluor (Ab150065, Abcam, Cambridge, United Kingdom) for $1 \mathrm{~h}$ at room temperature. Detection of the nucleus was done with 4, 6-diamidino-2-phenylindole (DAPI) (Sigma). Slides were washed in PBS and mounted using a minimal volume of medium (DAKO). Images were acquired with a Nikon C2 confocal microscope with 60x oil immersion lens. All regions of interest were imaged in the brain section. Densitometric analysis of images was performed with ImageJ $1.49 \mathrm{v}(\mathrm{NIH}$, USA). Nuclei were counted and fluorescence was measured.

\subsection{Behavioral test and pharmacological procedure}

The water maze consisted of a square pool filled with water $\left(5 \mathrm{~cm}\right.$ deep, $\left.25^{\circ} \mathrm{C}\right)$ divided by grey plastic walls to delimit 25 zones. Open doors allow communications between zones designing an ideal route from a starting zone to an exit with additional lateral error-zones. Each mouse was allowed to run the maze twice a day during 4 consecutive days (sessions $\mathrm{S} 1$ to $\mathrm{S} 4$ with a cut-off time of $2 \mathrm{~min}$ ). Parameters were recorded using a video-tracking system (Viewpoint, France). The time required to escape from the maze was named "escape latency". Adult males and females were used and were 12 months of age. A group of 6 mice was treated with SRT1720 $(50 \mathrm{mg} / \mathrm{kg}$ in $0,5 \mathrm{ml}$ dimethylsulfoxyde, $4,5 \mathrm{ml}$ polyethylene glycol $40040 \%$ in distillated water) every two days by oral administration during 2 weeks. Maze sessions occurred during the last week of treatment. As control, some mice received a corresponding vehicle dose 
(200 $\mu$ l). Treated animals received seven doses during the whole protocol and six doses before the beginning of the behavioral test. For a better clarity in the figure, the results of the vehicle groups were fused with their corresponding genetic groups, since the vehicle did not lead to any variation to wild-type or MTR-/- mice. All animal experiments were approved by the ethical committee for animal experiments of the Region Lorraine (Agreement \#12851-2017122215366738).

\subsection{Statistics}

Results were expressed as means + standard error of the mean. Comparison between cell phenotypes was performed by one-way ANOVA. For behavioral data, a two-ways ANOVA was applied according the different groups and treatments, followed by a Fischer's exact post-hoc analysis to obtain putative significances between groups ( $\mathrm{p}$ values).

\section{Results}

\subsection{Cellular stress of cblC and cblG fibroblasts leads to cytoplasmic localization of HuR}

Treatment of control fibroblasts with the G418 antibiotic led to the translocation of HuR from nucleus to cytoplasm. In contrast, in $c b l G$ patient fibroblasts, HuR was detected in both compartments and G418 produces no translocation. We confirmed that HuR localization resulted from a cellular stress by incubating control fibroblasts with the ER-stress inducer thapsigargin (Fig. 1A). Thapsigargin induced a cytoplasmic localization of HuR with a progressive shift that was already visible following $12 \mathrm{~h}$ of treatment, culminating with almost a complete lack of nuclear localization after $48 \mathrm{~h}$.

\section{2. cblC and cblG defects lead to SIRT1-mediated endoplasmic reticulum stress}

Our data show a strong increase of ATF6 activation, a typical mechanism of ER stress in $c b l C$ and in $c b l G^{*}$ fibroblasts, compared to control cells. Since ER stress could trigger HuR relocalization, we hypothesized that the partial cytoplasmic localization of HuR in $c b l G$ cells could be prevented by SIRT1 
activation. Thus, we quantified the cleavage of ATF6 in patient cells following incubation with cbl and the SIRT1 agonist SRT1720 (Fig. 1B). Both treatments with either Cbl or SRT1720 reduced the amount of ATF6 cleavage in $c b l C$ cells but only SRT1720 was effective in $c b l G^{*}$ fibroblasts.

\subsection{Inborn errors of cbl metabolism produce a mislocalization of RBPs related to cell stress}

In addition to HuR, we further investigated the subcellular localization of HnRNPA1, SRSF1 and Y14 in fibroblasts from three $\operatorname{cblC}(\mathrm{C} 1, \mathrm{C} 2, \mathrm{C} 3)$ and four $c b l G$ patients $(\mathrm{G} 1, \mathrm{G} 2, \mathrm{G} * 1, \mathrm{G} * 2)$ compared to one control cell line. HuR, HnRNPA1 and SRSF1 were selected for their roles in the cellular stress response while RBM10 and Y14 are not known to be involved in this pathway. Our results confirm the nuclear localization of HuR in control cells and show that HuR subcellular distribution is dramatically modified in all tested patient fibroblasts (Fig. 2, Supplementary Fig. 2). Interestingly, the shift towards a cytoplasmic localization is variable according to the patient cells with a complete absence of HuR in the nuclei, in fibroblasts from the $c b l G$ variant case. Our results also show the loss of nuclear localization for HnRNPA1 and RBM10 in all the tested fibroblasts (Fig. 2, Supplementary Fig. 2). In contrast, the subcellular localization of SRSF1 and Y14 was unaffected in the seven patient cells examined.

\subsection{Mislocalization of HuR, HnRNPA1 and RBM10 is rescued by vitamin B12, SAM and SRT1720} treatments

In order to confirm that the mislocalization of HuR, HnRNPA1 and RBM10 was the consequence of cellular stress induced by impaired cbl metabolism, we examined their subcellular localization in cells incubated with either SRT1720, vitamin B12 or S-adenosyl methionine (SAM). We found that the pharmacological activation of SIRT1 by SRT1720, vitamin B12 and SAM restored the nuclear localization of HuR, HnRNPA1 and RBM10 in all tested patient fibroblasts (Fig. 3, Supplementary Fig. 3). The effect of SAM suggested that the effect of altered B12 metabolism on RBPs subcellular localization was due to a mechanism related to impaired SAM-dependent methylation. 


\subsection{Inhibition of methylation does not lead to nucleocytoplasmic translocation of HuR, HnRNPA1}

and RBM10

In order to investigate specifically the effect of RBPs methylation status on their subcellular localization, we treated the fibroblasts with the inhibitor of methyltransferase, adenosine dialdehyde (Adox). As expected, this treatment decreased the methylation of HuR, HnRNPA1 and RBM10 in wild type cells (Fig. 3, Supplementary Fig. 3). However, the treatment of wild-type cells with Adox did not produce any cytoplasmic localization of HuR, suggesting that its nucleocytoplasmic translocation does not result from its altered methylation (Fig. 3). In contrast, in Adox-treated patient cells, HuR remained in the nuclei (Fig. 3), indicating that methylation is necessary for the nucleocytoplasmic transport of HuR.

\subsection{Nuclear localization of HuR, HnRNPA1 and RBM10 is restored by the PP2A inhibitor okadaic acid}

We previously reported that impaired cbl metabolism resulted in increased protein phosphatase PP2A expression and that the treatment of patient cells with the PP2A inhibitor okadaic acid (OA) restored the phosphorylation of $\mathrm{HuR}[11,13]$. Thus, we investigated the role of HuR phosphorylation on its subcellular localization by treating patient cells with OA. The treatment increased HuR phosphorylation and restored the nuclear staining of HuR in $c b l C$ patient fibroblasts, showing that impaired phosphorylation is a pathological mechanism involved in the RBPs mislocalization (Fig. 3).

\subsection{Decreased methylation and phosphorylation of HuR, HnRNPA1 and RBM10 is reversed by B12,} SAM and SRT1720 treatments

We examined the methylation and the phosphorylation of all the mislocalized RBPs in patient cells by co-immunoprecipitation with anti-methyl-arginine and anti-phospho-serine antibodies. Our results show a strong decrease of both methylated and phosphorylated forms of HuR, HnRNPA1 and RBM10 in $c b l C, c b l G$ and $c b l G^{*}$ fibroblasts (Fig. 4A, Supplementary Fig. 4A). These data showed that the posttranslational modifications of RBPs were associated to the altered nucleocytoplasmic shuttling of RBPs in inborn errors of cbl metabolism. 
To confirm the role of cbl impaired metabolism on the methylation of RBP, we examined the effect of either vitamin B12 or SAM on the methylation and the phosphorylation of HuR, HnRNPA1 and RBM10 in control cells and $c b l C, c b l G$ and $c b l G^{*}$ fibroblasts. The incubation of patient fibroblasts with either vitamin B12 or SAM was able to restore the methylation and phosphorylation of the 3 RBPs (Fig. 4B, Supplementary Fig. 4B). Interestingly, the activation of SIRT1 by SRT1720 treatment was also partially effective in the rescue of these post-translational modifications.

\subsection{Impaired RBPs function in cblC, $c b l G$ and $c b l G^{*}$ patients is restored by adding B12, SAM or} SRT1720

Since the mislocalization of RBPs could affect their functions, we investigated the localization of mRNA by performing FISH staining of poly-A mRNA. Our results showed a predominant nuclear localization of mRNA in control fibroblasts and a mixed perinuclear and cytoplasmic localization in patient cells (Fig. 5A). Moreover, the treatment of patient fibroblasts with SRT1720, B12 and SAM restored the nuclear localization of poly-A mRNAs (Fig. 5A, Supplementary Fig. 5).

In addition to the consequences on mRNA shuttling, it may be expected that the mislocalization of RBP may alter the proper splicing of the target mRNAs. For example, knock-down of HnRNPAI increases the skipping of exons 2 (type I) and 3 (type 3) of Interferon Regulatory Factor-3 (IRF3) premRNA [14]. We therefore studied the splicing of $I R F 3$ as an example of the consequences of RBPs mislocalization in patient fibroblasts. RT-PCR amplification of $I R F 3$ generated three different products, a full-length product of $500 \mathrm{bp}$ (FL) containing the exons 1 to 4, a first splicing type I variant of $327 \mathrm{bp}$ with exclusion of exon 2 and a type II variant of 155 bp with exclusion of exon 2 and exon 3 (Fig. 5B). As expected, in wild type cells, IRF3 RT-PCR generated almost only the FL isoform while a decrease of the ratio $\mathrm{FL} /(\mathrm{FL}+\mathrm{I}+\mathrm{II})$ was observed in $c b l G$ and $c b l G^{*}$ fibroblasts. Interestingly, this ratio was corrected following incubation of $c b l G$ and $c b l G^{*}$ cells with SRT1720 (Fig. 5B) B12 vitamin and SAM (Supplementary Fig. 5). 


\subsection{SIRT1 expression and HuR subcellular localization are altered in the mouse model of methionine}

synthase deficiency in the brain

Using a cellular model with impaired cbl availability, we previously demonstrated that the altered nucleo-cytoplasmic shuttling of RBP leads to SIRT1-dependent dramatic transcriptomic changes affecting neurogenesis, neuron differentiation, and neuroplasticity [13]. Therefore, we further investigated the effect of SIRT1 pharmacological activation on the altered neuroplasticity resulting from impaired vitamin B12 metabolism in an original transgenic mouse model of methionine synthase deficiency specific to neuronal cells (Fig. 6A). The efficiency of our construct was validated by the analysis of Mtr expression by RT-qPCR that revealed a significant decrease of Mtr mRNA levels in the cortex and the hippocampus of homozygous Mtr KO mice (Fig. 6B). Western blot analysis of MTR in 72 mice revealed that $30 \%$ of the animals did not present a significative decrease of the protein while $54 \%$ of them expressed less than $10 \%$ of the protein compared to controls (data not shown). Immunohistochemical analysis of different regions of the brain indicated that SIRT1 expression was significantly decreased in the CA1 subfield of the hippocampus but not in the dentate gyrus, CA2, CA3, cortex and cerebellum (Fig. 6C). In order to evaluate the effect of the SIRT1-activating compound, a group of mice was treated with $50 \mathrm{mg} / \mathrm{kg}$ of SRT1720 every two days by oral administration during 2 weeks. Our results indicated that this treatment was able to restore the level of SIRT1 in the CA1 region (Fig. 6C, 6D). Then, we evaluated the activation of SIRT1 by SRT1720 on cellular stress and RBP mislocalization by analyzing the subcellular distribution of HuR. We showed a decreased nuclear localization of HuR in Mtr KO mice compared to wild type mice. This result is consistent with an impaired nucleocytoplasmic translocation of HuR in response to cellular stress. This hallmark was partly rescued in the brain from Mtr KO mice treated with SRT1720 (Fig. 6E).

\subsection{Pharmacological activation of SIRT1 improves the cognitive defects of the brain-Mtr KO mice}

The learning performance of control and Mtr $\mathrm{KO}$ mice was evaluated using a water maze in which the animals were evaluated twice a day during four consecutive days (Fig. 7A). The results, expressed as the 
time required to exit the maze, show that control mice achieved efficient cognitive performance since they present a shorter escape latency from session 2 to session 4 (Fig. 7B). On the other hand, Mtr KO mice showed poor cognitive performance even in session $\mathrm{S} 4(\mathrm{P}<0.003)$. The treatment of Mtr KO mice with the SIRT agonist reduced dramatically the cognitive deficit from session $3(\mathrm{P}<0.003)$. The cumulative traces of the video-tracking recording confirmed the phenotype of the Mtr KO and the effect of SRT1720 on their cognitive performance (Fig. 7A).

\section{Discussion}

The ER stress of fibroblasts from patients with inborn errors of cbl cellular metabolism was evidenced by activation of the ATF6 pathway. This was consistent with previous results obtained in N1E115 TO cells [13]. ER stress may be triggered by the oxidative stress that results from the increased ROS production [16]. The accumulation of homocysteine produced by cbl deficiency could also lead to increased homocysteinylation of proteins. This protein adduct mechanism increases protein aggregation and ER stress [17]. Moreover, we found previously that the cbl impaired cellular availability in N1E115 TO cell induces ER stress by greater acetylation of HSF1 through decreased SIRT1 expression, whereas adding vitamin B12 produces protective effects. The increased acetylation of HSF1 leads to critical reduction of the expression of molecular chaperones that modulate ER stress [18].

Our data showed that inborn errors of cbl metabolism could trigger the cytoplasmic accumulation of RBP associated with ER stress. HuR and HnRNPA1 are two RBP involved in the response to cell stress. HuR is ubiquitously expressed and it is involved in various biological processes such as proliferation and stress response, and in mRNA metabolism processes that include splicing, polyadenylation, translation and miRNA repression [19]. The HnRNPA1 protein belongs to the splicing regulator (SR) and heterogeneous nuclear ribonucleoprotein (hnRNP) classes that is predominantly located in the nucleus. 
While it was initially known for its contribution to mRNA splicing regulation, HnRNPA1 also acts as trans-acting factor involved in translation initiation of specific mRNAs through its binding to internal ribosome entry sites (IRES) following stress stimuli [20, 21]. Interestingly, the function of HnRNPA1 proteins on regulating alternative splicing by the use of alternative 5' splice sites is balanced by the relative amount of SRSF1 [22]. The SRSF1 protein, also called ASF/SF2, is a member of the SR proteins involved in the regulation of general and alternative splicing, nonsense-mediated mRNA decay and mRNA export [23]. It has been demonstrated that stress stimuli result in cytoplasmic accumulation of HnRNPA1 in contrast to SRSF1 [24]. This finding is consistent with our data showing no difference in subcellular localization of SRSF1 between patient fibroblasts and control cells and supports the idea that the mislocalization of HnRNPA1 could have functional consequences. We observed also a mislocalization of RBM10 in all patient cells. In contrast to HuR and HnRNPA1, RBM10 is not a cellular stress RBP. It is a member of the RNA-binding motif (RBM) gene family, which contains several functional domains involved in RNA or protein binding interactions, including with components of prespliceosomal A and B complexes [25]. Several studies have highlighted an extensive role of RBM10 in alternative splicing $[26,27]$. Thus, the mislocalization of RBM10 in patient cells could participate in deregulation of alternative splicing of target gene transcription in $c b l C$ and $c b l G$ defects. In contrast to HuR, HnRNPA1 and RBM10, Y14 was not mislocalized in patient cells. This may be explained by the absence of methylation and phosphorylation changes of Y14 in patient fibroblasts, in contrast to HuR, HnRNPA1 and RBM10.

$\mathrm{Cbl}$ and SAM treatment resulted in the rescue of methylation, phosphorylation and subcellular localization of HuR, HnRNPA1 and RBM10. This confirmed the key role of decreased methylation and phosphorylation in the abnormal subcellular localization of these RBPs. The treatment of wild-type cells with the methylation inhibitor AdoX did not lead to HuR mislocalization while it resulted in nuclear localization of $\mathrm{HuR}$ in the stressed $c b l C$ cells by impairing the nucleocytoplasmic shuttling of Hur that should be associated with cellular stress. In contrast, the inhibition of phosphatases by okadaic acid treatment restored the nuclear localization of HuR in patient cells. These data are similar to those obtained 
in the mouse N1E115 neuroblastoma cells [13]. They showed that phosphorylation has a prominent role in the nucleocytoplasmic shuttling and subcellular localization of RBP and RNA in stressed cells of patients while decreased methylation alone has a modulating but no mandatory role in this shuttling. Indeed, our data support the numerous studies highlighting the importance of post-translational modifications in the regulation of HuR function, including phosphorylation of serine and threonine residues $[28,29]$.

The inborn errors of cbl metabolism produced altered nucleo-cytoplasmic shuttling of mRNAs and splicing of IRF3 that were consistent with the RBP cytoplasmic mislocalization. The loss of nuclear localization and increased cytoplasmic localization of HuR, HnRNPA1 and RBM10 produces a mislocalization of mRNA that is involved in pathological mechanisms of other genetic diseases with neurological manifestations. Mutations affecting the HnRNPAl gene have been associated with amyotrophic lateral sclerosis [30]. Among them, it has been shown that a specific mutation affecting the nuclear localization signal (NLS) of HnRNPA1 could lead to permanent cytoplasm localization and most likely to pathogenic loss of function in a patient who presented with flail arm syndrome (FAS), an atypical and mild subtype of amyotrophic lateral sclerosis characterized with progressive and symmetric weakness of the upper limbs but with no significant lower limb disability [31]. It is noticeable that some $c b l C$ and $c b l G$ cases may have neurological manifestations that mimic mild forms of amyotrophic lateral sclerosis [32]. In addition, methylcobalamin prevented the death of motor neurons derived from embryonic stem cell co-cultivated with astrocytes expressing mutant human superoxide dismutase-1 (G93A) [33]. RBM10 null mutations affect early embryonic development and could lead to the X-linked recessive disorder TARP syndrome associated with hearing loss, optic atrophy and structural brain abnormalities [34]. Interestingly, an in-frame deletion of RBM10 found in a TARP patient has been associated with the loss of nuclear localization and accumulation in the cytosol, strongly suggesting that the abnormal subcellular localization of RBM10 could be responsible for pathogenic loss of function [26]. The altered splicing of IRF3 may be an example of a general deregulation of RNA splicing produced by 
inborn errors of cbl metabolism. IRF3 splicing is regulated by HnRNPA1 [14]. We also observed an abnormal splicing of $I R F 3$ with skipping of exons 2 and 3 in $c b l G$ and in $c b l G^{*}$ fibroblasts (Fig. 5B). IRF gene codes for a transcriptional activator for type I interferons and the truncated isoforms produced by alternative splicing are known to inhibit the full-length gene product [14]. Taken together, the dramatic alterations of mRNA shuttling and splicing could contribute to explain the great variability of clinical manifestations and response to therapy of inborn errors of cbl metabolism.

The impaired cbl metabolism leads to RBP mislocalization and subsequent transcriptomic changes mainly affecting genes involved in neurogenesis, synapse transmission, brain development, and neuroplasticity, in NIE-115 and patient cells. These data led us to investigate the effect of SIRT1 activation on the cognitive defects associated with the genetic defects of cbl metabolism in a mice model of $c b l G$ with conditional invalidation of Mtr in the brain. The invalidation of Mtr produced a decreased expression of SIRT1 in the hippocampus. The subsequent alteration of the localization of HuR and the hippocampo-dependent learning ability, were corrected by the administration of SRT1720. Similarly, Wang et al showed that SRT1720 treatment could reduce the cognitive decline in type 2 diabetic rats, probably through a Nrf2-NFkB dependent mechanism [35]. Thus, our study suggests that the beneficial effect of SRT1720 on the cognitive performance of the Mtr KO mice results from the rescue of RBPs proper localization through its protective effects against ER stress. They are consistent with the beneficial effects of SRT1720 recently described on neuroplasticity, including axon growth, dendritic arborization and neurite outgrowth [36].

\section{Conclusions}

Taken together, our data show a common scenario of the molecular consequences of the inborn errors of cbl cellular metabolism with reduced MS activity. The oxidant stress and decreased expression of SIRT1 produce ER stress and a subsequent mislocalization of RBP through decreased methylation and phosphorylation leading to deregulation of RNA trafficking and splicing (Supplementary Fig. 6). These 
pathological mechanisms were reversed by pharmacological activation of SIRT1 in patient cells in vitro but also in vivo in a mouse model of methionine synthase deficiency. Indeed, we showed that SRT1720 treatment could partially rescue the cognitive defects observed in these mice. Thus, our work opens perspectives for the use of SIRT1 activating compounds as a novel therapeutic strategy to treat inborn errors of cbl metabolism especially for patients with poor response to conventional therapy. For many of these patients, a good treatment response effect on metabolic markers does not include significant improvement of neurological and psychiatric symptoms [6], highlighting the need for an alternative therapeutic approach.

\section{Acknowledgment}

We thank D.R. Rosenblatt (McGill, Montreal) and M.R. Baumgartner (University Children's Hospital, Zürich) for providing patient fibroblasts.

\section{Funding}

This work was supported by fundings from Fondation Jérôme Lejeune, CHRU Nancy Hospital and Région Lorraine.

\section{Conflict-of-interest/financial disclosure statement}

None.

\section{Authors contributions}

J.L.G. and D.C. conceived the study. J.L.G., D.C., and R.G. wrote the manuscript. R.G., S.F.B.H., N.D., F.F., J.L.G. and D.C. contributed to the experimental design and interpretation of data. 
R.G., C.B., A.W., J.F., A.R. and N.D. contributed to the fibroblast studies. C.A., I.T. and G.P. contributed to the mouse studies.

Current address of R. Ghemrawi: College of Pharmacy, Al Ain University, 112612 Abu Dhabi, UAE.

\begin{abstract}
Abbreviations
ABCD4, ATP Binding Cassette Subfamily D Member 4; AdoCbl, adenosylcobalamin; Adox, adenosine dialdehyde; ATF6, Activating Transcription Factor 6; ELAVL1, ELAV Like RNA Binding Protein 1; ER, endoplasmic reticulum; FISH, Fluorescence In Situ Hybridization; HnRNPA1, Heterogeneous Nuclear Ribonucleoprotein A1; HSF1, Heat Shock Transcription Factor 1; HuR, Hu-Antigen R, ELAVL1; IRF3, Interferon Regulatory Factor-3; LMBD1, LMBR1 domain-containing protein; MeCbl, methylcobalamin; MTR, 5-Methyltetrahydrofolate-Homocysteine Methyltransferase; MTRR, 5Methyltetrahydrofolate-Homocysteine Methyltransferase Reductase; OA, okadaic acid; PLA, proximity ligation assay; PP2A, Protein Phosphatase 2 Phosphatase Activator; RBM10, RNA Binding Motif Protein 10; RBP, RNA binding protein; SAM, S-adenosyl methionine; SIRT1, Sirtuin 1; SRSF1, Serine and Arginine Rich Splicing Factor 1; SSC, Saline Sodium Citrate buffer; TG, thapsigargin.
\end{abstract}

\title{
Legends to Figures
}

Fig. 1. Effect of thapsigargin on the subcellular localization of HuR in control fibroblasts and effect of vitamin B12 and SRT1720 on ATF6 cleavage in $c b l C$ and in $c b l G^{*}$ patient fibroblasts. (A) Following exposure to thapsigargin ( $1 \mu \mathrm{M}, 3$ days), cells were stained with anti-HuR and DAPI at different time points and visualized by confocal microscopy. (B) Fibroblasts from control (WT), $c b l C$ and $c b l G^{*}$ patients were incubated with B12 vitamin (hydroxocobalamin $20 \mu \mathrm{M}, 5$ days) or with SRT1720 (1 $\mu$ M, 3 days) and submitted to western blotting against the activated form of ATF6. Alpha tubulin was used as an 
internal control of protein expression. Densitometric analysis of three different Western blots shows the quantification of cleaved ATF6.

Fig. 2. Subcellular localization of selected RNA binding proteins. Fibroblasts from control, and from three patients $\left(c b l C 1, c b l G 1\right.$ and $\left.c b l G^{* 2}\right)$ patients were stained with anti-HuR, anti-RBM10 and antiHnRNPA1 and visualized by confocal microscopy.

Fig. 3. Effect of SRT1720, vitamin B12, SAM, AdoX and okadaic acid on the subcellular localization of HuR. Fibroblasts from control and from one $c b l C$ patient were incubated with SRT1720 (1 $\mu \mathrm{M}, 3$ days), B12 vitamin (hydroxocobalamin $20 \mu \mathrm{M}, 5$ days), SAM (75 $\mu \mathrm{M}, 5$ days), AdoX (1 $\mu \mathrm{M})$ and okadaic acid (OA, $10 \mathrm{nM})$, stained with anti-HuR and visualized by confocal microscopy.

Fig. 4. Effect of SRT1720, vitamin B12, SAM, AdoX and okadaic acid treatments on the methylation and on the phosphorylation of HuR, HnRNPA1 and RBM10. (A) Control (WT) $c b l C, c b l G$ and $c b l G^{*}$ fibroblasts extracts were immuno-precipitated with anti-methyl-arginine or phosphor-serine antibodies and submitted to western blotting against HuR, HnRNPA1, RBM10 and Y14 proteins. (B) Similarly, in addition to the IgG control and to non -treated cells (NT), each cell line was treated with SRT1720 (SRT, $1 \mu \mathrm{M}), \mathrm{B} 12$ vitamin $(\mathrm{B} 12,20 \mu \mathrm{M}), \mathrm{SAM}(75 \mu \mathrm{M})$ and $\operatorname{AdoX}(1 \mu \mathrm{M})$ for the detection of the methylated forms of HuR, HnRNPA1 and RBM10 or with SRT1720 (SRT), B12 vitamin (B12), SAM and okadaic acid $(\mathrm{OA}, 10 \mathrm{nM})$ for the detection of the phosphorylated forms of the same RNA binding proteins.

Fig. 5. Effect of SRT1720 on mRNA localization and effects of SRT1720, vitamin B12 and SAM treatments on IRF3 splicing. (A) Control (WT), $c b l C, c b l G$ and $c b l G^{*}$ fibroblasts were treated with SRT1720 ( $1 \mu \mathrm{M}, 3$ days), and submitted to FISH assay with poly A probes and stained with DAPI before visualization by confocal microscopy. (B) Alternative splicing of IRF3 in control (WT), $c b l C, c b l G$ and $c b l G^{*}$ fibroblasts. Control and $c b l G^{*}$ cells were treated with SRT1720 (1 $\mu \mathrm{M}, 3$ days), B12 vitamin 
(hydroxocobalamin $20 \mu \mathrm{M}, 5$ days) and SAM (75 $\mu \mathrm{M}, 5$ days). RT-PCR of IRF3 was performed with specific primers (Guo et al, 2013) designed to amplify three different products: a full-length product of $500 \mathrm{bp}$ (FL) containing the exons 1 to 4, a first splicing variant of 327 bp (Type I: exclusion of exon 2) and a second variant of 155 bp (Type II: exclusion of exon 2 and exon 3 and expressed by the ratio $\mathrm{FL} /(\mathrm{FL}+\mathrm{I}+\mathrm{II})$. T test, $* \mathrm{P}<0.05, * * \mathrm{P}<0.005, \mathrm{P} * * *<0.0005$.

Fig. 6. Mtr knock-out mouse model, SIRT1 expression in the brain and effect of SRT1720 treatment on the cognitive function. (A) Genetic strategy for the Mtr knock-out mouse model. The construct was inserted into the genomic region by homologous recombination (grey crosses). In the construct, two LoxP sites are flanking the exons 4 and 5 of the Mtr gene. Following Cre recombination between the two LoxP sites, these two exons are removed and a frameshift occurs in exon 6. (B) Mtr mRNA quantitation by RTqPCR in the cortex and hippocampus of WT and Mtr-KO mice (n=6) P $<0.001$. (C) Quantification of the SIRT1 protein by immunofluorescence (green) in different cerebral regions of WT and Mtr-KO mice following SRT1720 treatment. T test, $* \mathrm{P}<0.05,{ }^{*} * \mathrm{P}<0.01 * * * \mathrm{P}<0.001$ (D). Immunofluorescence staining of SIRT1 (green) in WT and Mtr-KO mice following SRT1720 treatment in the CA1 zone of the hippocampus. Confocal microscopy with x60 objective. Scale bars (white dash) represent $10 \mu \mathrm{m}$. (E). Immunofluorescence staining of HuR (green) in WT and Mtr-KO mice following SRT1720 treatment in the CA1 zone of the hippocampus. Confocal microscopy with x60 objective. Scale bars (white dash) represent $10 \mu \mathrm{m}$.

Fig. 7. Effect of SRT1720 treatment on the cognitive performance of brain Mtr-KO mice (A). Upper view of the water maze with the ideal route from the start-box to the home-cage. Every other square zone represents errors and waste of time and examples of cumulative traces of mice in the maze at the end of the training sessions (hippocampo-dependent learning procedure). The red color indicates a rapid speed while the green color indicates a slow speed and even several stops on the walls of the maze. (B) Escape latency of the mice in the aquatic maze. Histograms represent the time required for the mice to exit from 
the aquatic maze. WT: wild type mouse; Mtr KO: brain Mtr knock-out mouse; Mtr KO + SRT1720: brain Mtr knock-out mouse treated by SRT1720 as described in the Material and Methods section. Each group is composed of at least 6 mice. Parameters were recorded using a video-tracking system (Viewpoint, France). ANOVA, $* \mathrm{P}<0.05, * * \mathrm{P}<0.005$.

\section{References}

1. Watkins D, Rosenblatt DS (2013) Lessons in biology from patients with inborn errors of vitamin B12 metabolism. Biochimie 95, 1019-1022. DOI: 10.1016/j.biochi.2016.05.001

2. Coelho D, Kim JC, Miousse IR, Fung S, du Moulin M, Buers I, Suormala T, Burda P, Frapolli M, Stucki M, Nürnberg P, Thiele H, Robenek H, Höhne W, Longo N, Pasquali M, Mengel E, Watkins D, Shoubridge EA, Majewski J, Rosenblatt DS, Fowler B, Rutsch F, Baumgartner MR (2012) Mutations in ABCD4 cause a new inborn error of vitamin B12 metabolism. Nat. Genet. 44, 11521155. DOI: $10.1038 / \mathrm{ng} .2386$

3. Coelho D, Suormala T, Stucki M, Lerner-Ellis JP, Rosenblatt DS, Newbold R, Baumgartner MR, Fowler B (2008) Gene identification for the cblD defect of vitamin B12 metabolism. N. Engl. J. Med. 358, 1454-1464. DOI: 10.1056/NEJMoa072200

4. Lerner-Ellis JP, Tirone JC, Pawelek PD, Doré C, Atkinson JL, Watkins D, Morel CF, Fujiwara TM, Moras E, Hosack AR, Dunbar GV, Antonicka H, Forgetta V, Dobson CM, Leclerc D, Gravel RA, Shoubridge EA, Coulton JW, Lepage P, Rommens JM, Morgan K, Rosenblatt DS (2006) Identification of the gene responsible for methylmalonic aciduria and homocystinuria, cblC type. Nat. Genet. 38, 93-100. DOI: 10.1038/ng1683 
5. Fischer S, Huemer M, Baumgartner M, Deodato F, Ballhausen D, Boneh A, Burlina AB, Cerone R, Garcia P, Gökçay G, Grünewald S, Häberle J, Jaeken J, Ketteridge D, Lindner M, Mandel H, Martinelli D, Martins EG, Schwab KO, Gruenert SC, Schwahn BC, Sztriha L, Tomaske M, Trefz F, Vilarinho L, Rosenblatt DS, Fowler B, Dionisi-Vici C. (2014) Clinical presentation and outcome in a series of 88 patients with the cblC defect. J. Inherit. Metab. Dis. 37, 831-480. DOI: 10.1007/s10545014-9687-6

6. Huemer M, Bürer C, Ješina P, Kožich V, Landol MA, Suormala T, Fowler , AugoustidesSavvopoulou P, Blair E, Brennerova K, Broomfield A, De Meirleir L, Gökcay G, Hennermann J, Jardine P, Koch J, Lorenzl S, Lotz-Havla AS, Noss J, Parini R, Peters H, Plecko B, Ramos FJ, Schlune A, Tsiakas K, Zerjav Tansek M, Baumgartner MR (2015) Clinical onset and course, response to treatment and outcome in 24 patients with the cblE or cblG remethylation defect complemented by genetic and in vitro enzyme study data. J. Inherit. Metab. Dis. 38, 957-967. DOI: $10.1007 / \mathrm{s} 10545-014-9803-7$

7. Sillaots SL, Hall CA, Hurteloup V, Rosenblatt DS (1992) Heterogeneity in cblG: differential retention of cobalamin on methionine synthase. Biochem. Med. Metab. Biol. 47, 242-249.

8. Richard E, Alvarez-Barrientos A, Pérez B, Desviat LR, Ugarte M (2007) Methylmalonic acidaemia leads to increased production of reactive oxygen species and induction of apoptosis through the mitochondrial/caspase pathway. J. Pathol. 213, 453-461. DOI: 10.1002/path.2248

9. Richard E, Desviat LR, Ugarte M, Pérez N. (2013) Oxidative stress and apoptosis in homocystinuria patients with genetic remethylation defects. J. Cell Biochem. 114, 183-191. DOI: 10.1002/jcb.24316 
10. 10.Jorge-Finnigan A, Gámez A, Pérez B, Ugarte M, Richard E (2010) Different altered pattern expression of genes related to apoptosis in isolated methylmalonic aciduria cblB type and combined with homocystinuria cblC type. Biochim. Biophys. Acta 1802, 959-967. DOI:

10.1016/j.bbadis.2010.08.002

11. Battaglia-Hsu SF, Akchiche N, Noel N, Alberto JM, Jeannesson E, Orozco-Barrios CE, MartinezFong D, Daval JL, Guéant JL (2009) Vitamin B12 deficiency reduces proliferation and promotes differentiation of neuroblastoma cells and up-regulates PP2A, proNGF, and TACE. Proc. Natl. Acad. Sci. U.S.A. 106, 21930-21935. DOI: 10.1073/pnas.0811794106

12. Ghemrawi R, Pooya S, Lorentz S, Gauchotte G, Arnold C, Guéant JL, Battaglia-Hsu SF (2013) Decreased vitamin B12 availability induces ER stress through impaired SIRT1-deacetylation of HSF1. Cell Death Dis. 4, e553. DOI: 10.1038/cddis.2013.69

13. Battaglia-Hsu SF, Ghemrawi R, Coelho D, Dreumont N, Mosca P, Hergalant, Gauchotte G, Sequeira JM, Ndiongue M, Houlgatte R, Alberto JM, Umoret R, Robert A, Paoli J, Jung M, Quadros EV, Guéant JL (2018) Inherited disorders of cobalamin metabolism disrupt nucleocytoplasmic transport of mRNA through impaired methylation/phosphorylation of ELAVL1. Nucleic Acids Res. 46, 7844-7857. DOI: 10.1093/nar/gky634

14. Guo R, Li Y, Ning J, Sun D, Lin L, Liu X (2013) HnRNP A1/A2 and SF2/ASF regulate alternative splicing of interferon regulatory factor-3 and affect immunomodulatory functions in human nonsmall cell lung cancer cells. PLoS One 8, e62729. DOI: 10.1371/journal.pone.0062729

15. Milne JC, Lambert PD, Schenk S, Carney DP, Smith JJ, Gagne DJ, Jin L, Boss O, Perni RB, Vu CB, Bemis JE, Xie R, Disch JS, Ng PY, Nunes JJ, Lynch AV, Yang H, Galonek H, Israelian K, Choy W, 
Iffland A, Lavu S, Medvedik O, Sinclair DA, Olefsky JM, Jirousek MR, Elliott PJ, Westphal CH (2007) Small molecule activators of SIRT1 as therapeutics for the treatment of type 2 diabetes. Nature 450, 712-716. DOI: 10.1038/nature06261

16. Richard E, Jorge-Finnigan A, Garcia-Villoria J, Merinero B, Desviat LR, Gort L, Briones P, Leal F, Pérez-Cerdá C, Ribes A, Ugarte M, Pérez B; MMACHC Working Group. (2009) Genetic and cellular studies of oxidative stress in methylmalonic aciduria (MMA) cobalamin deficiency type C (cblC) with homocystinuria (MMACHC). Hum. Mutat. 30, 1558-1566. DOI: 10.1002/humu.21107

17. Jakubowski H. (2019) Homocysteine Modification in Protein Structure/Function and Human Disease. Physiol. Rev. 99, 555-604. DOI: 10.1152/physrev.00003.2018

18. Guéant JL, Elakoum R, Ziegler, Coelho D, Feigerlova E, Daval JL, Guéant-Rodriguez RM (2014) Nutritional models of foetal programming and nutrigenomic and epigenomic dysregulations of fatty acid metabolism in the liver and heart. Pflugers Arch. 466, 833-850. DOI: 10.1007/s00424-013$1339-4$

19. Meisner NC, Filipowicz W (2011) Properties of the Regulatory RNA-Binding Protein HuR and its Role in Controlling miRNA Repression. Adv. Exp. Med. Biol. 700, 106-123. DOI: 10.1007/978-14419-7823-3_10

20. Cammas A, Pileur F, Bonnal S, Lewis SM, Lévêque N, Holcik M, Vagner S. (2007) Cytoplasmic relocalization of heterogeneous nuclear ribonucleoprotein A1 controls translation initiation of specific mRNAs. Mol. Biol. Cell 18, 5048-5059. DOI: 10.1091/mbc.e07-06-0603 
21. Guil S, Long JC, Caceres JF (2006) hnRNP A1 relocalization to the stress granules reflects a role in the stress response. Mol. Cell. Bio. 26, 5744-5758. DOI: 10.1128/MCB.00224-06

22. Mayeda A, Krainer AR (1992) Regulation of alternative pre-mRNA splicing by hnRNP A1 and splicing factor SF2. Cell 68, 365-375. DOI: 10.1016/0092-8674(92)90477-t

23. Sinha R, Allemand E, Zhang Z, Karni R, Myers MP, Krainer AR (2010) Arginine methylation controls the subcellular localization and functions of the oncoprotein splicing factor SF2/ASF. Mol. Cell. Biol. 30, 2762-2674. DOI: 10.1128/MCB.01270-09

24. Van der Houven van Oordt W, Diaz-Meco MT, Lozano J, Krainer AR, Moscat J, Cáceres JF (2000) The MKK(3/6)-p38-signaling cascade alters the subcellular distribution of hnRNP A1 and modulates alternative splicing regulation. J. Cell. Biol. 149, 307-316. DOI: 10.1083/jcb.149.2.307

25. Bessonov S, Anokhina M, Will CL, Urlaub H, Lührmann R (2008) Isolation of an active step I spliceosome and composition of its RNP core. Nature 452, 846-850. DOI: 10.1038/nature06842

26. Wang Y, Gogol-Döring A, Hu H, Fröhler S, Ma Y, Jens M, Maaskola J, Murakawa Y, Quedenau C, Landthaler M, Kalscheuer V, Wieczorek D, Wang Y, Hu Y, Chen W (2013) Integrative analysis revealed the molecular mechanism underlying RBM10-mediated splicing regulation. EMBO Mol. Med. 5, 1431-1442. DOI: 10.1002/emmm.201302663

27. Inoue A, Yamamoto N, Kimura M, Nishio K, Yamane H, Nakajima K (2014) RBM10 regulates alternative splicing. FEBS Lett. 588, 942-947. DOI: 10.1016/j.febslet.2014.01.052 
28. Abdelmohsen K, Pullmann R Jr, Lal A, Kim HH, Galban S, Yang X, Blethrow JD, Walker M, Shubert J, Gillespie DA, Furneaux H, Gorospe M. (2007) Phosphorylation of HuR by Chk2 regulates SIRT1 expression. Mol. Cell. 25, 543-557. DOI: 10.1016/j.molcel.2007.01.011

29. Grammatikakis I, Abdelmohsen K, Gorospe M (2017) Posttranslational control of HuR function. Wiley Interdiscip. Rev. RNA. Epub 2016 Jun 16. DOI: 10.1002/wrna.1372

30. Kim HJ, Kim NC, Wang YD, Scarborough EA, Moore J, Diaz Z, MacLea KS, Freibaum B, Li S, Molliex A, Kanagaraj AP, Carter R, Boylan KB, Wojtas AM, Rademakers R, Pinkus JL, Greenberg SA, Trojanowski JQ, Traynor BJ, Smith BN, Topp S, Gkazi AS, Miller J, Shaw CE, Kottlors M, Kirschner J, Pestronk A, Li YR, Ford AF, Gitler AD, Benatar M, King OD, Kimonis VE, Ross ED, Weihl CC, Shorter J, Taylor JP (2013) Mutations in prion-like domains in hnRNPA2B1 and HnRNPA1 cause multisystem proteinopathy and ALS. Nature 495, 467-473. DOI: $10.1038 /$ nature 11922

31. Liu Q, Shu S, Wang RR, Liu F, Cui B, Guo XN, Lu CX, Li XG, Liu MS, Peng B, Cui LY, Zhang X (2016) Whole-exome sequencing identifies a missense mutation in HnRNPA1 in a family with flail arm ALS. Neurology 87, 1763-1769. DOI: 10.1212/WNL.0000000000003256

32. Mirian, A, Korngut L. (2018) The Utility of the Laboratory Work Up at the Time of Diagnosis of Amyotrophic Lateral Sclerosis. J. Neuromuscul. Dis. 5, 35-38. DOI: 10.3233/JND-170281

33. Ito S, Izumi Y, Niidome T, Ono Y (2017) Methylcobalamin prevents mutant superoxide dismutase1-induced motor neuron death in vitro. Neuroreport. 28, 101-107. DOI: 10.1097/WNR.0000000000000716 
34. Johnston JJ, Teer JK, Cherukuri PF, Hansen NF, Loftus SK, NIH Intramural Sequencing Center (NISC), Chong K, Mullikin J, Biesecker LG (2010) Massively parallel sequencing of exons on the X chromosome identifies RBM10 as the gene that causes a syndromic form of cleft palate. Am. J. Hum. Genet. 86, 743-748. DOI: 10.1016/j.ajhg.2010.04.007

35. Wang F, Shang Y, Zhang R, Gao X, Zeng Q (2018) A SIRT1 agonist reduces cognitive decline in type 2 diabetic rats through antioxidative and anti-inflammatory mechanisms. Mol. Med. Rep. Epub ahead of print. DOI: 10.3892/mmr.2018.9699

36. Lee J, Ko YU, Chung Y, Yun N, Kim M, Kim K, Oh YJ (2018) The acetylation of cyclin-dependent kinase 5 at lysine 33 regulates kinase activity and neurite length in hippocampal neurons. Sci. Rep. 8, 13676. DOI: $10.1038 / \mathrm{s} 41598-018-31785-9$

37. Fofou-Caillierez MB, Mrabet NT, Chéry C, Dreumont N, Flayac J, Pupavac M, Paoli J, Alberto JM, Coelho D, Camadro JM, Feillet F, Watkins D, Fowler B, Rosenblatt DS, Guéant JL (2013) Interaction between methionine synthase isoforms and MMACHC: characterization in cblG-variant, cblG and cblC inherited causes of megaloblastic anaemia. Hum. Mol. Genet. 22, 4591-4601. DOI: $10.1093 / \mathrm{hmg} / \mathrm{ddt} 308$

38. Bassila C, Ghemrawi R, Flayac J, Froese DS, Baumgartner MR, Guéant JL, Coelho D (2017) Methionine synthase and methionine synthase reductase interact with MMACHC and with MMADHC. Biochim. Biophys. Acta Mol. Basis Dis. 1863, 103-112. DOI:

10.1016/j.bbadis.2016.10.016

39. Watkins D, Ru M, Hwang HY, Kim CD, Murray A, Philip NS, Kim W, Legakis H, Wai T, Hilton JF, Ge B, Doré C, Hosack A, Wilson A, Gravel RA, Shane B, Hudson TJ, Rosenblatt DS (2002) 
Hyperhomocysteinemia due to methionine synthase deficiency, cblG: structure of the MTR gene, genotype diversity, and recognition of a common mutation, P1173L. Am. J. Hum. Genet. 71, 143153. DOI: $10.1086 / 341354$ 
A

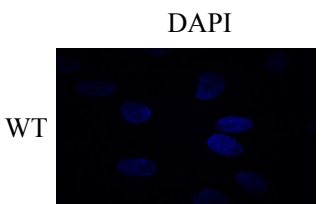

$2 \mathrm{~h}$

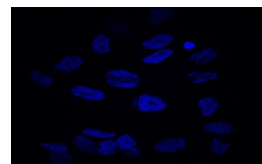

$24 \mathrm{~h}$

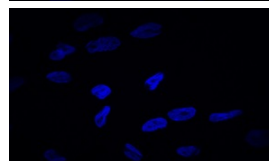

$36 \mathrm{~h}$

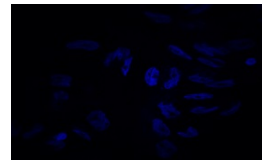

$48 \mathrm{~h}$

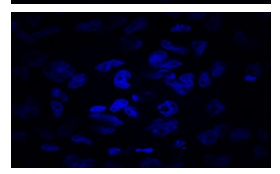

HuR
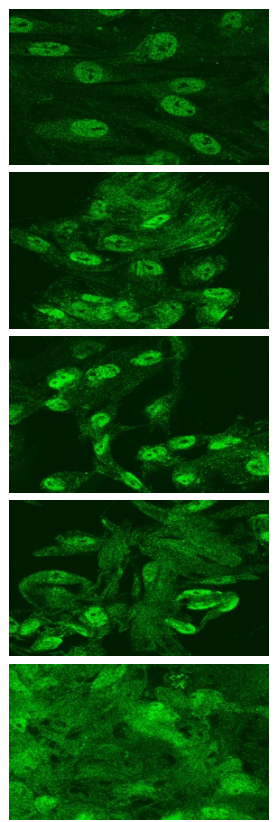

Merged
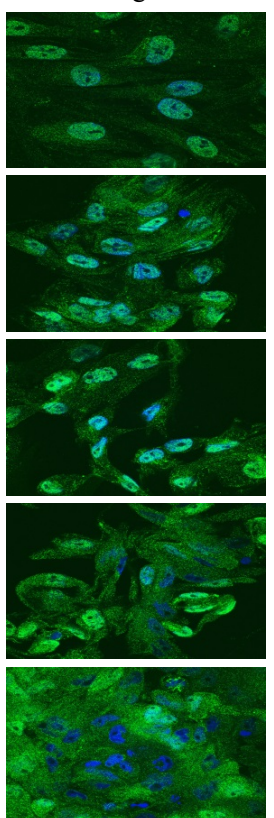

B

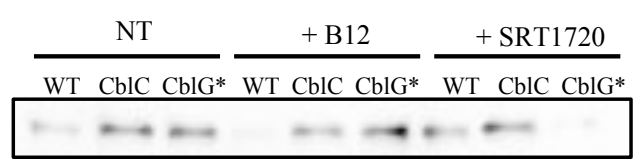
ATF6

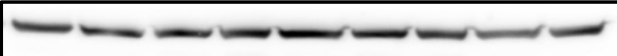
Alpha tubulin

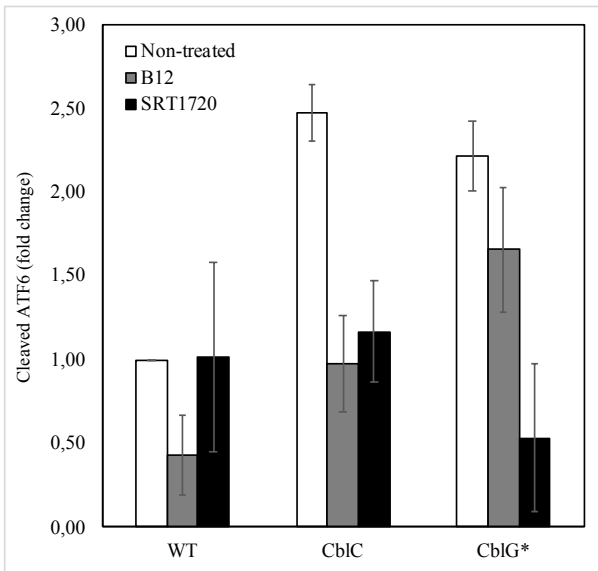




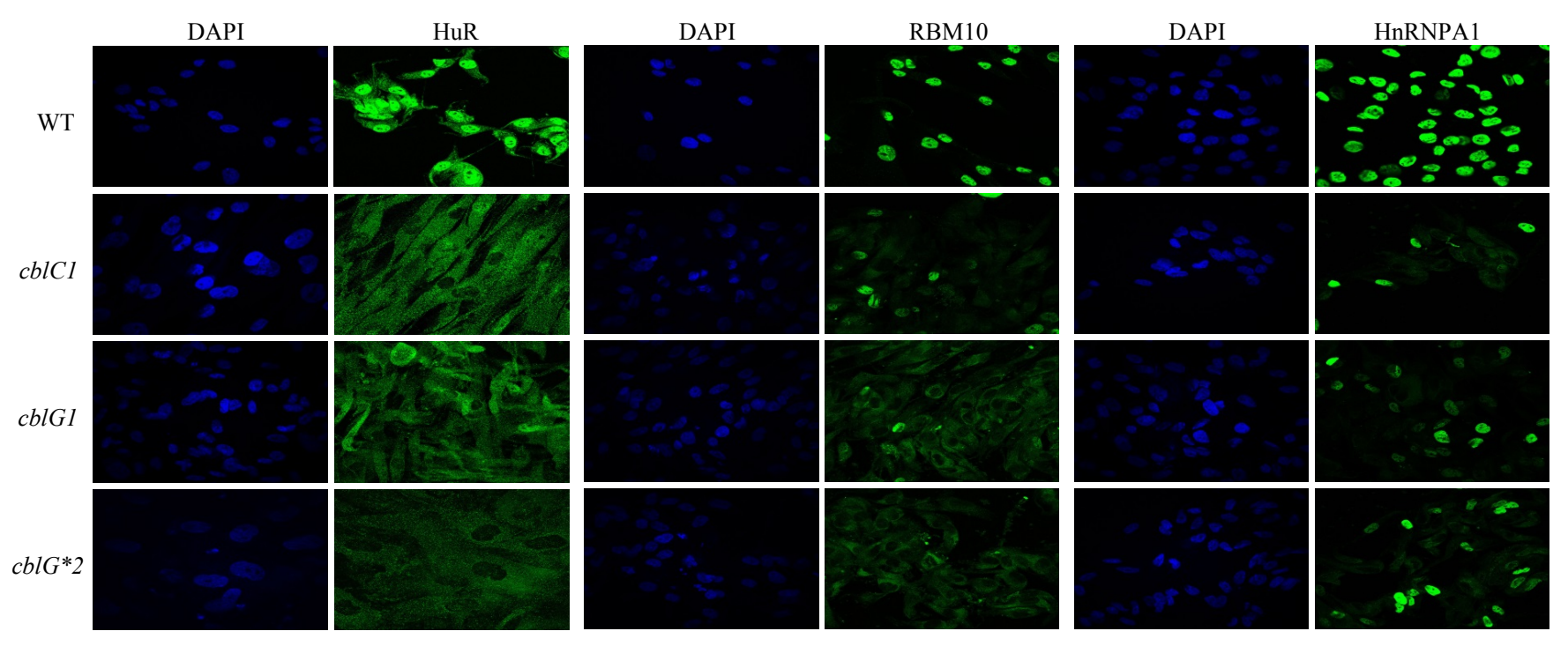




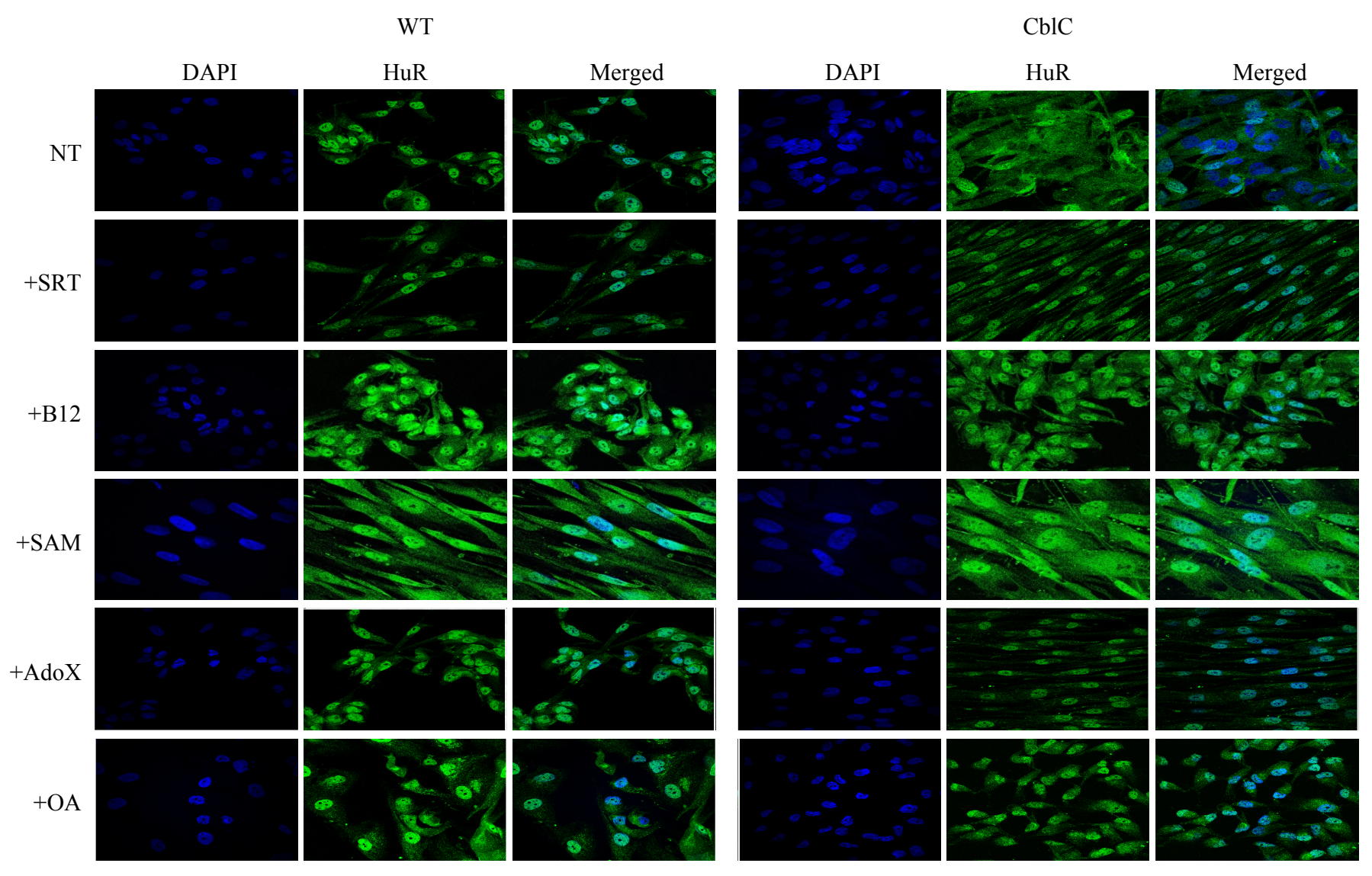




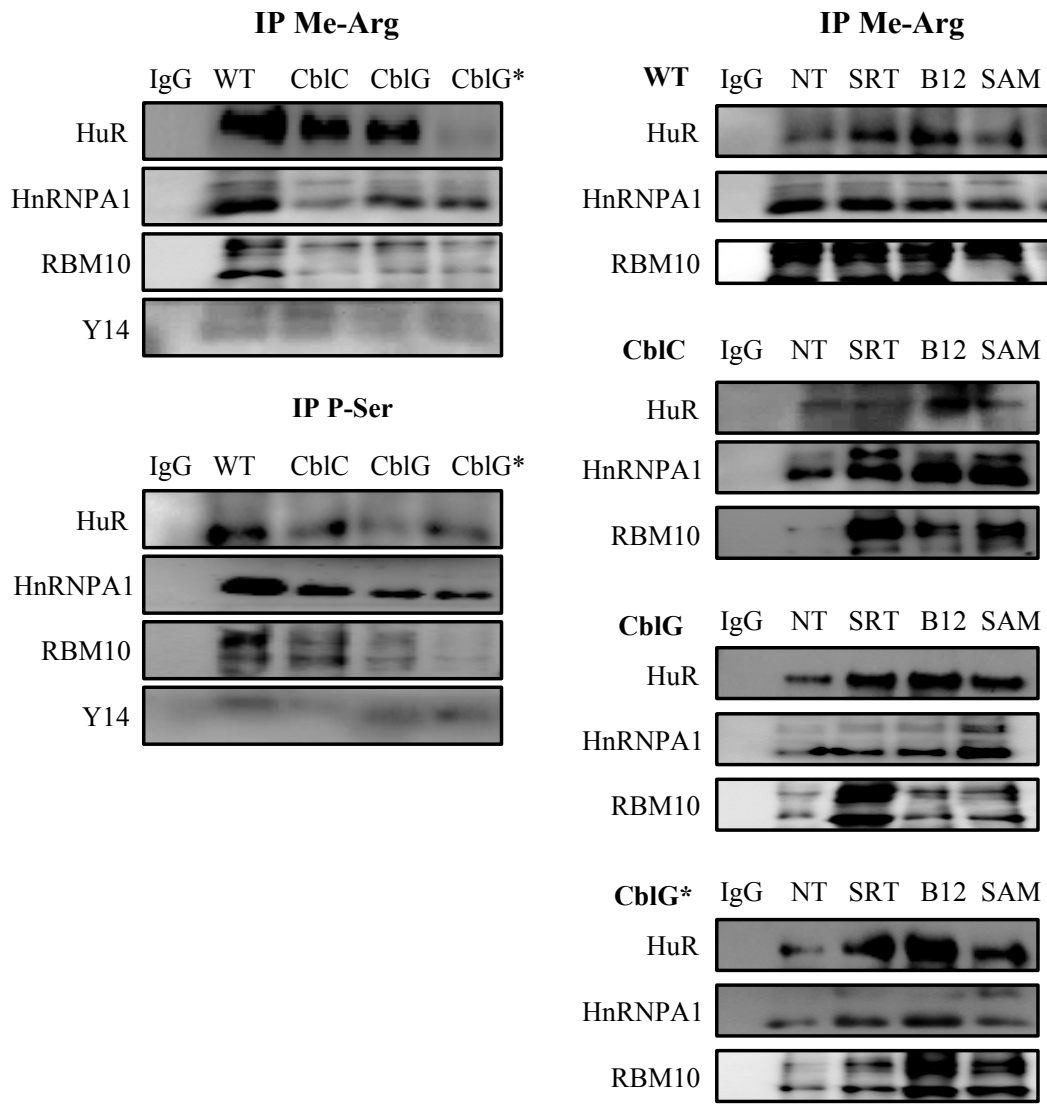

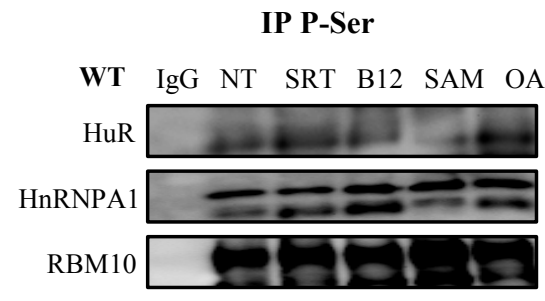
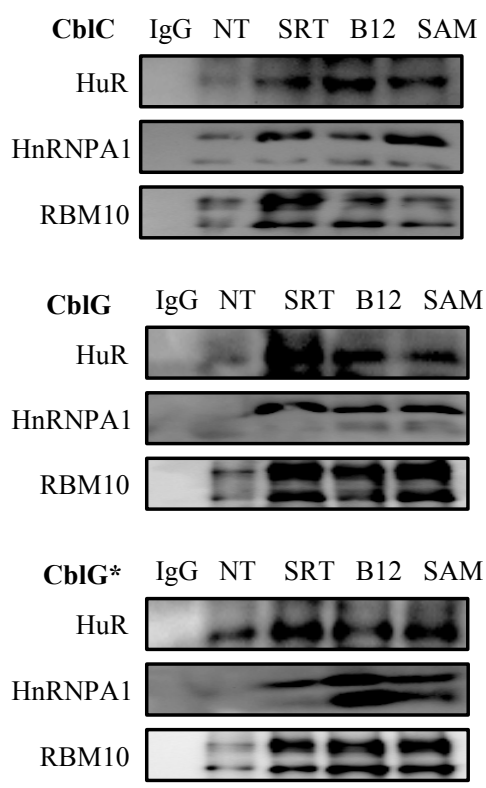
A

FISH

DAPI
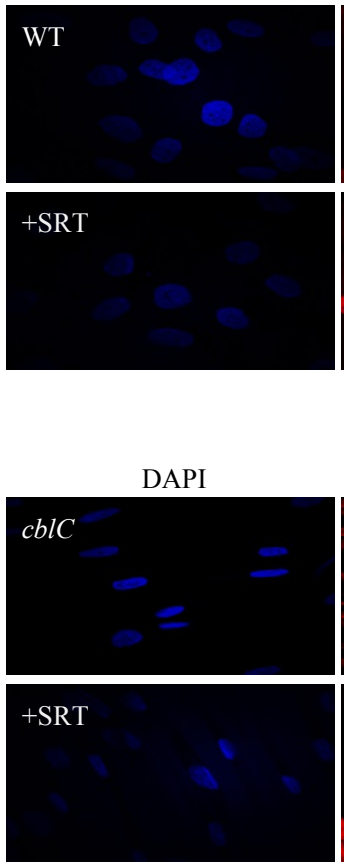

Poly A probes

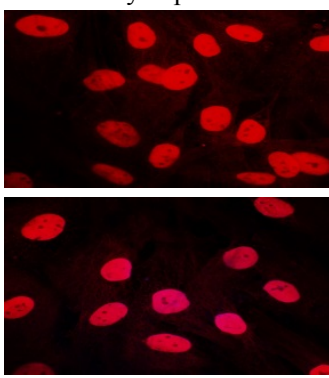

FISH

Poly A probes

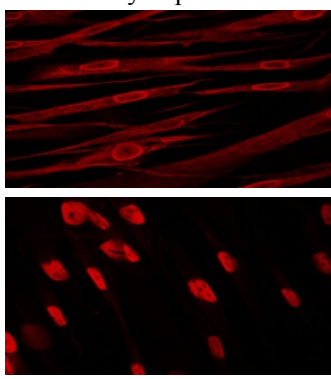

FISH

Poly A probes
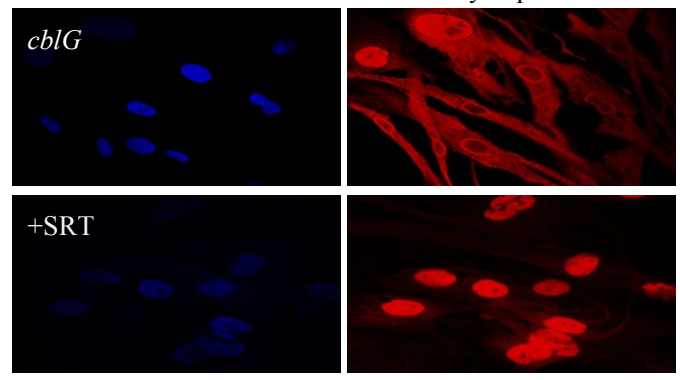

FISH

Poly A probes
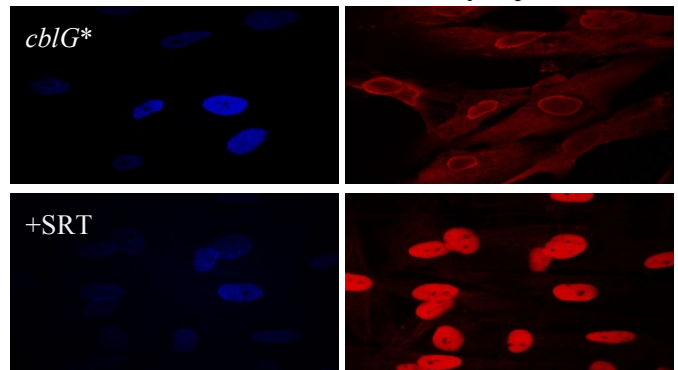

B

WT

cblG*
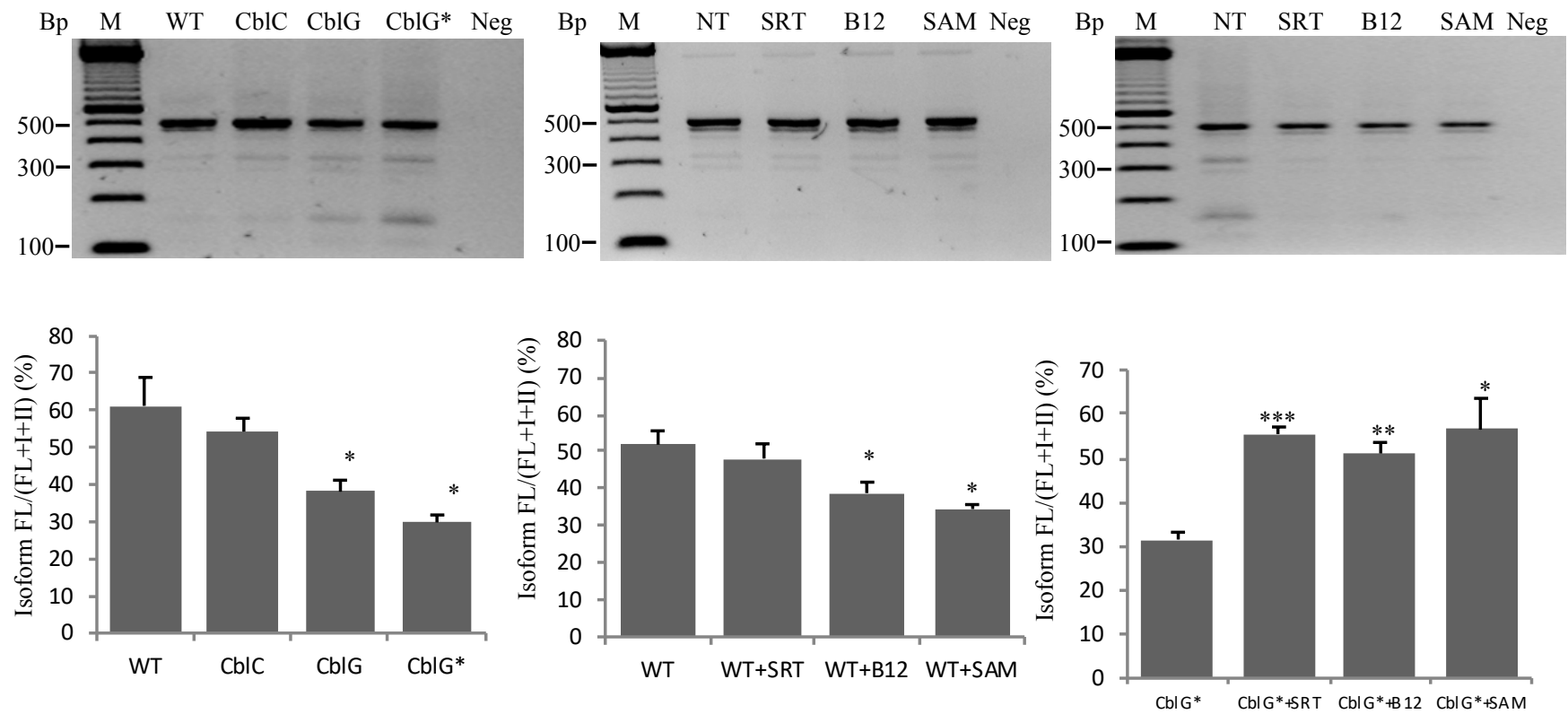
A

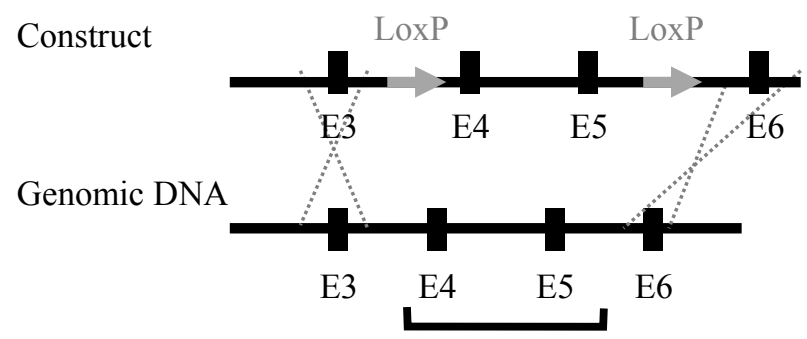

Knock-out region (2.6 kb)

Genomic DNA after

Cre recombination

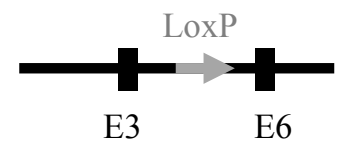




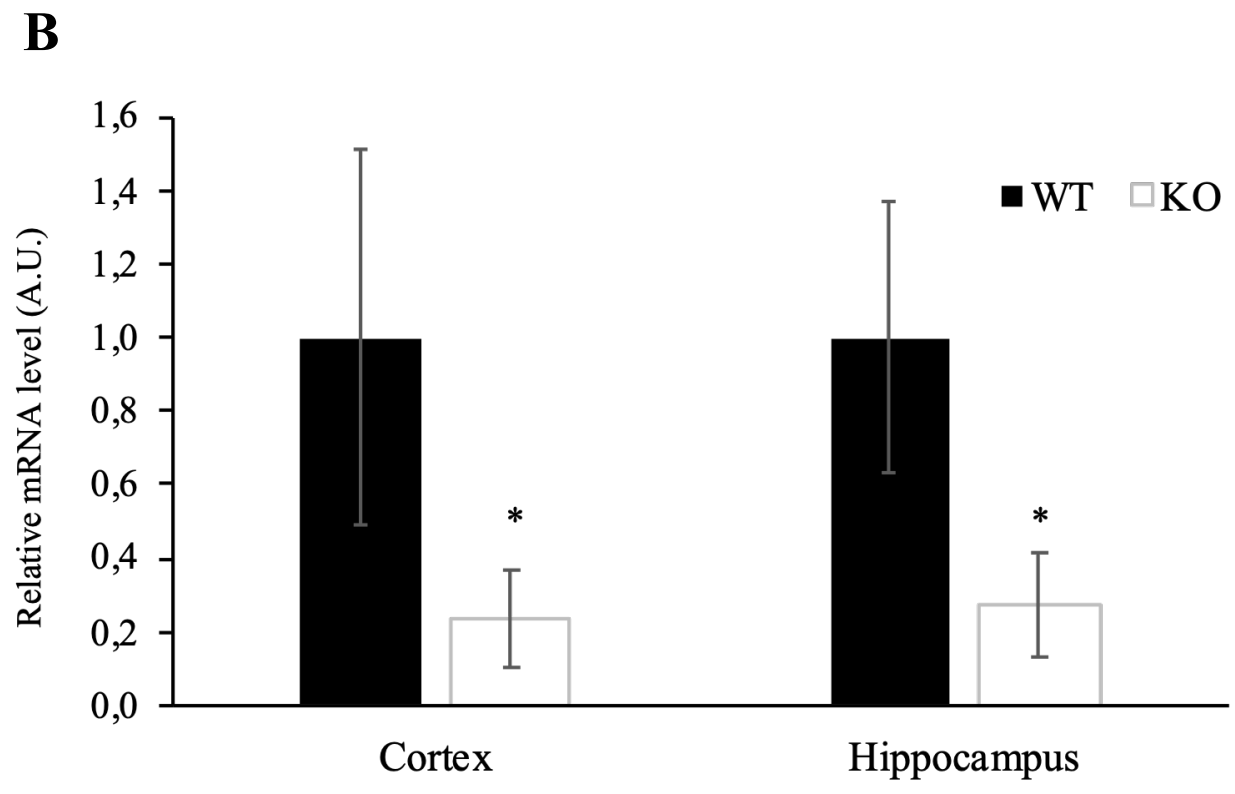


C

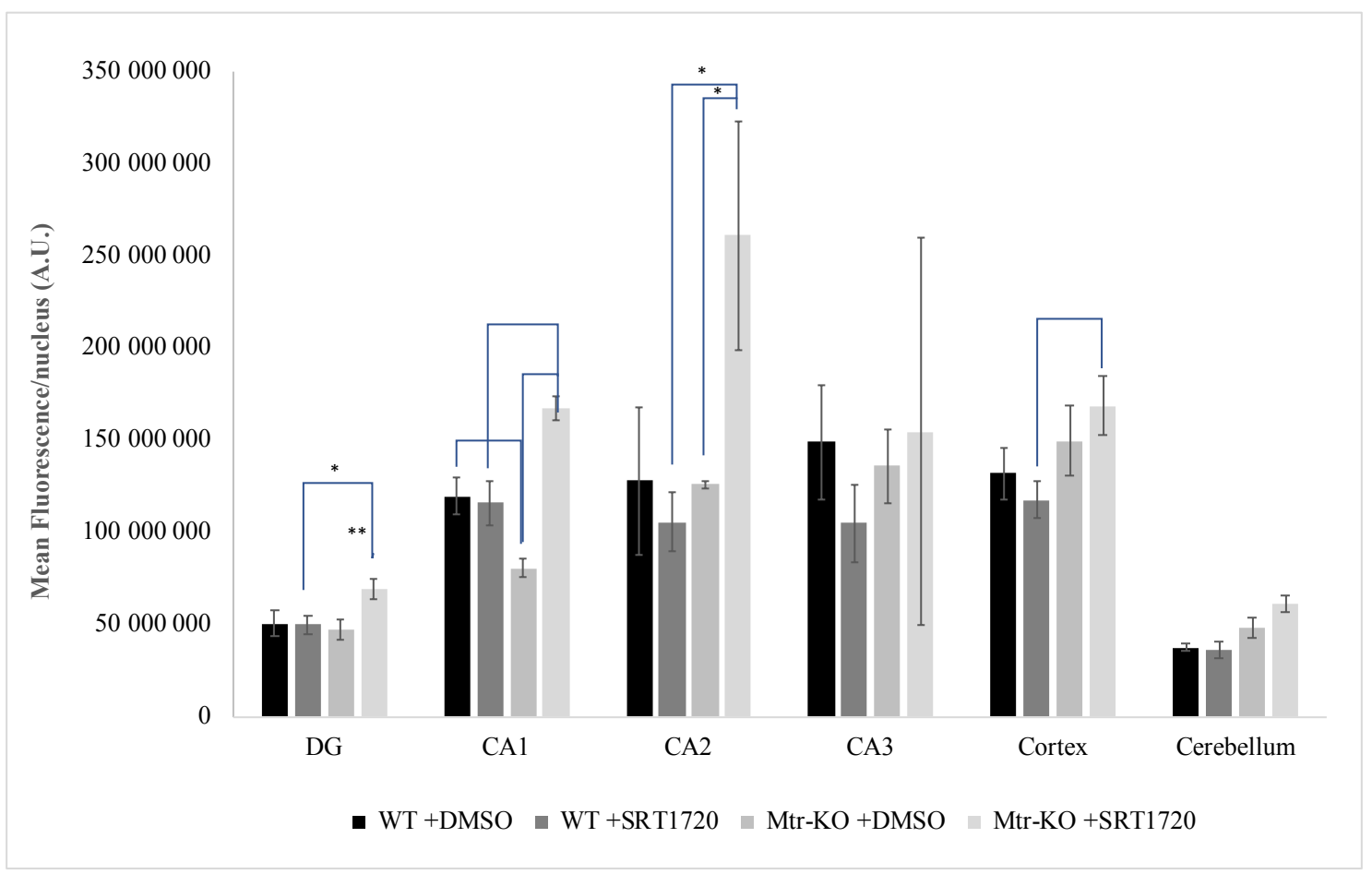


D

Merge

DAPI

SIRT1

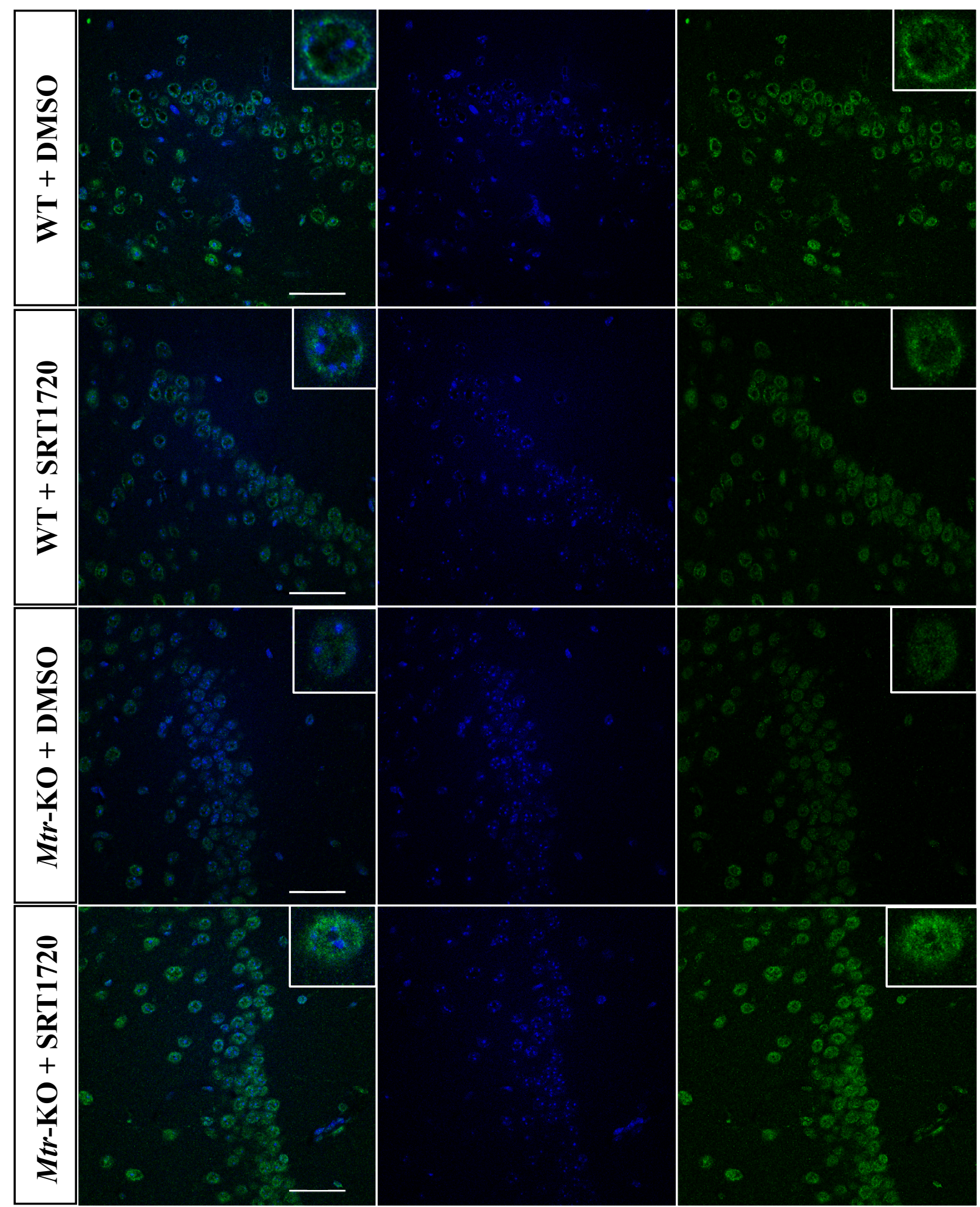


E

Merge

DAPI

HuR

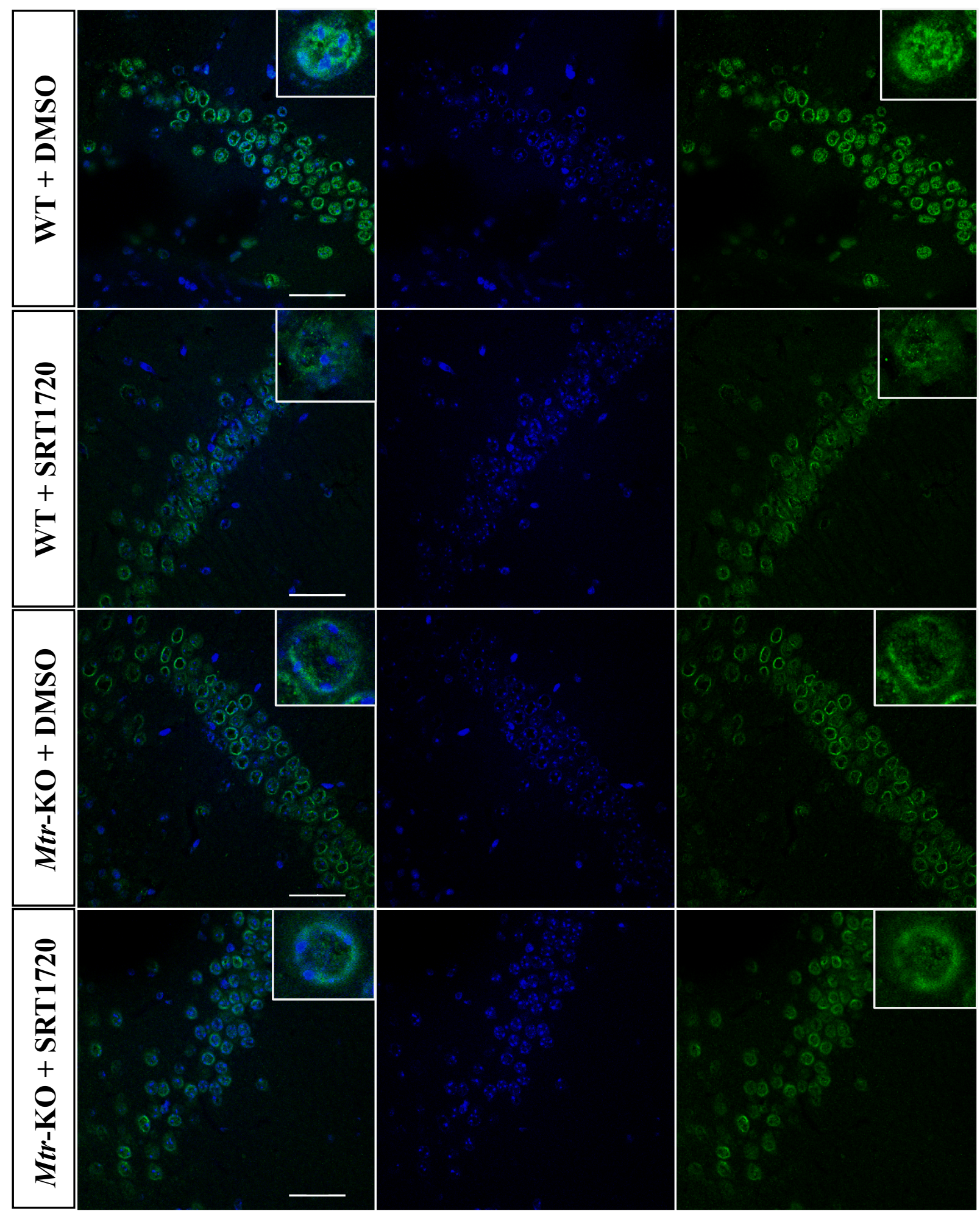


A
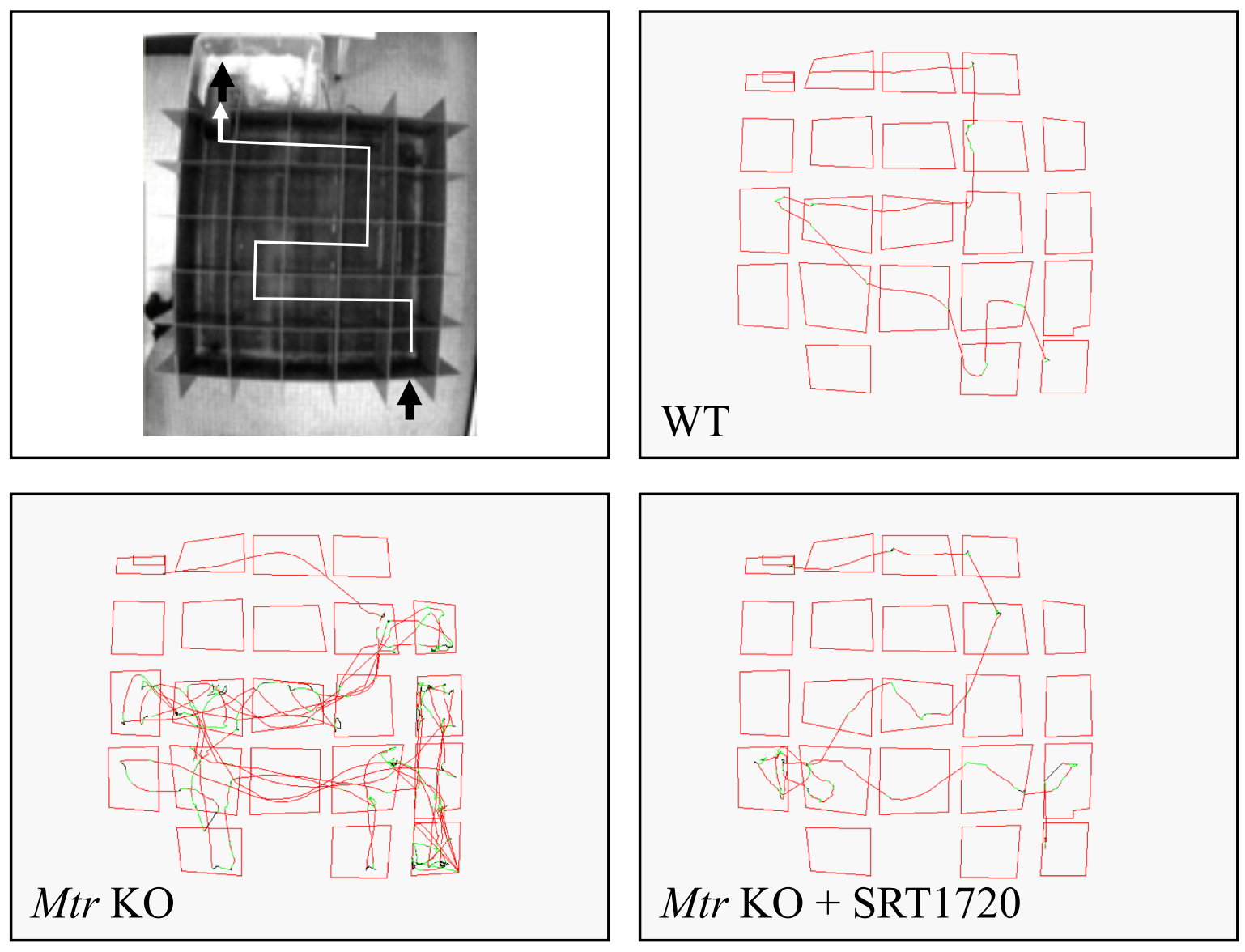

B

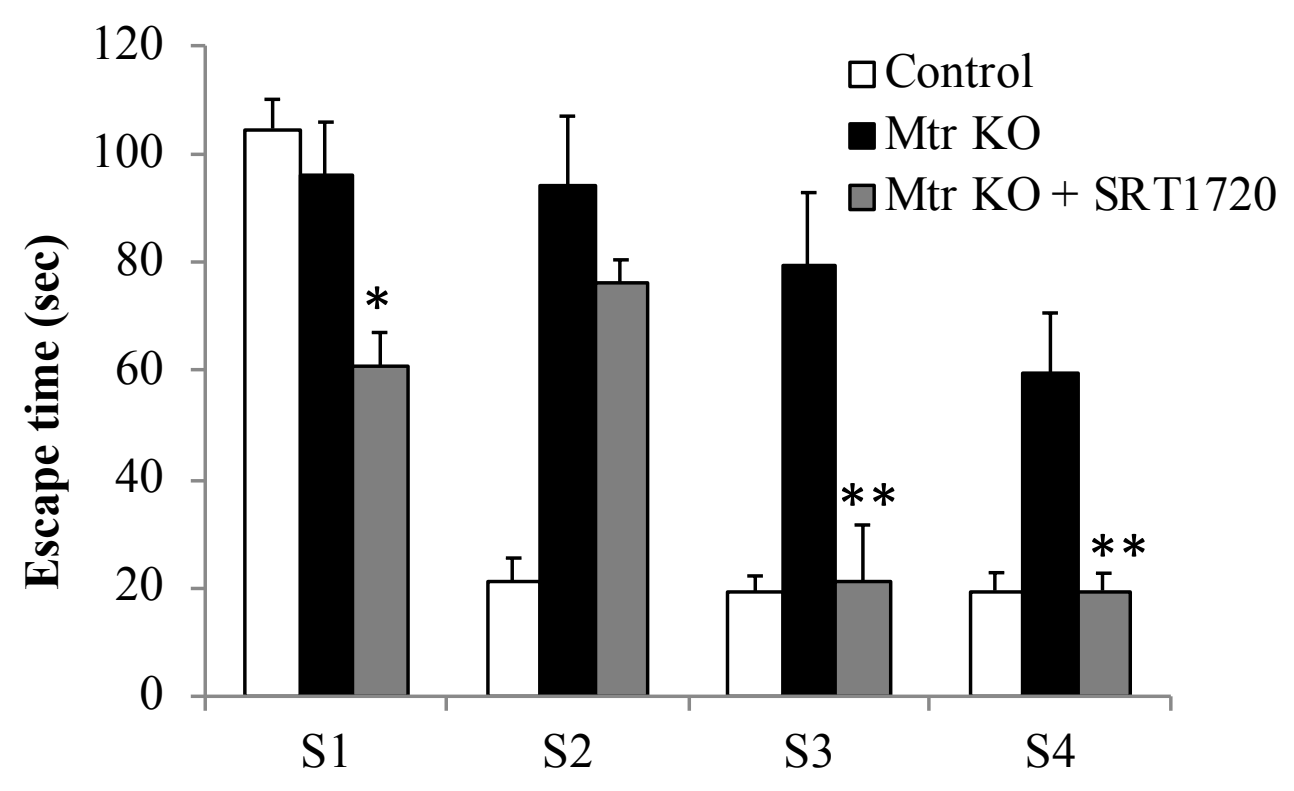

